Int. J. Dev. Biol. 52: 1059-1075 (2008)

doi: $10.1387 /$ ijdb.072439ls

\title{
Segmenting the fly embryo: logical analysis of the role of the Segment Polarity cross-regulatory module
}

\author{
LUCAS SÁNCHEZ ${ }^{1}{ }^{*}$, CLAUDINE CHAOUIYA ${ }^{2}$ and DENIS THIEFFRY ${ }^{2}$ \\ ${ }^{1}$ Centro de Investigaciones Biológicas (C.S.I.C.), Madrid, Spain and \\ ${ }^{2}$ U928 - TAGC / INSERM \& Université de la Méditerranée, Parc Scientifique de Luminy, Marseille, France
}

\begin{abstract}
Initially activated by the pair-rule genes, the expression patterns of the segment polarity genes engrailed and wingless become consolidated through inter-cellular interactions between juxtaposed cells. We delineate a logical model focusing on a dozen molecular components at the core of the regulatory network controlling this process. Our model leads to the following conclusions: (1) the pair-rule signals, which activate engrailed and wingless genes independently of each other, need to be operative until the inter-cellular circuit involving these two genes is functional. This implies that the pair-rule pattern is instrumental both in determining the activation of the genes engrailed and wingless in rows of adjacent cells, and in consolidating these expression patterns; (2) the consolidation of engrailed and wingless expression patterns requires the simultaneous activation of both autocrine and paracrine Wingless-pathways, and the Hedgehog pathway; (3) protein kinase A plays at least two roles through the phosphorylation of Cubitus interruptus, the effector molecule of the Hedgehog signalling pathway and (4) the roles of Sloppy-paired and Naked in the delineation of the engrailed and wingless expression domains are emphasized as being important for segmental boundary formation. Moreover, the application of an original computational method leads to the delineation of a subset of crucial regulatory circuits enabling the coexistence of specific expression states at the cellular level, as well as specific combination of cellular states inter-connected through Wingless and Hedgehog signalling. Finally, the simulation of altered expressions of segment polarity genes leads to results consistent with the published data.
\end{abstract}

KEY WORDS: Drosophila, systems biology, pattern formation, segmentation, regulatory circuit

\section{Introduction}

The Drosophila embryo encompasses a series of repeated units (segments). The first signs of segmentation are transient grooves (visible on the surface of the embryo after gastrulation) (Martínez-Arias and Lawrence, 1985). This initial (para)segmental organisation of the embryo gives rise to the overt segments shown by the larva and later on by the adult. The posterior portion of one segment plus the anterior portion of the next posterior segment originate from one individual embryonic parasegment. Parasegments thus span the same length as segments, but their borders lie between the segment boundaries.

Segmentation originates from the action of maternal organisers on zygotic genes (reviewed in Ingham and Martínez-Arias, 1992; Pankratz and Jäckle, 1993; Sprenger and Nüsslein-Volhard,
1993; Rivera-Pomar and Jäckle, 1996). These zygotic segmentation genes can be classified into three categories depending on the number of segments affected by their mutations. Mutations in gapgenes affect several contiguous segments, while the pair-rule gene mutations delete complete alternate segments. Finally, the segment polaritygenes affect each segment. Each of these three sets of genes forms a cross-regulatory module wherein all genes are involved in intertwined feedback circuits (for a discussion on genetic cross-regulatory modules, see Thieffry and Sánchez, 2004). These modules form a hierarchical system in which interactions take place in a temporal order. The maternal products involved in segmentation act upon the zygotic genome, resulting

Abbreviations used in this paper: Abr, Abbreviation; Abrs, Abbreviations.

*Address correspondence to: Lucas Sánchez. Centro de Investigaciones Biológicas, Ramiro de Maeztu, 9, 28040 Madrid, Spain.
Fax: 34-91-536-0432. e-mail: Isanchez@cib.csic.es

Electronic Supplementary Material for this article, consisting of 3 supplementary figures, is available at: http://dx.doi.org/10.1387/ijdb.072439ls

Published online: 21 st July 2008

$0214-6282 / 2008 / \$ 35.00$

(C) UBC Press

Printed in Spain 
in the activation of gap genes. Maternal and gap factors control the activation of pair-rule genes. Finally, pair-rule genes control the expression of segment polarity genes, ultimately determining which cells will express engrailed (en)in juxtaposition to cells that express wingless (wg) along the anterior-posterior axis of the embryo trunk. The juxtaposition of these two types of cells determines the formation of the parasegmental boundaries: cells expressing en mark the anterior (posterior) region of each parasegment (segment) and cells expressing wgmark the posterior (anterior) region of each parasegment (segment).

The formation of parasegments occurs at the blastoderm stage. When the embryo cellularises, the blastomeres become able to express either enor wgin response to the pair-rulesignal, with the main role played by even-skipped and fushi-tarazu (reviewed in Ingham, 1991; Ingham and Martínez-Arias, 1992; for a model analysis, see Sánchez and Thieffry, 2003). The pair-rule products activate the genes $e n$ and $w g$ in 14 adjacent narrow stripes along the anterior-posterior region of the embryo trunk. The initial activation of $e$ and $w g$ is independent of each other, but the consolidation of their expressions depends upon inter-cellular regulatory interactions: the expression of en requires the expression of $w g$ in the anterior adjacent cells and the expression of $w g$ requires the expression of enin the posterior adjacent cells. Thus, the originally independent expression patterns become dependent upon each other. Later in development, when the segments are already formed, the expressions of $e n$ and $w g$ become again independent of each other.

Two other genes, sloppy-pairedand naked, may be critical in limiting the competence of these cells to receive the cell-specifying signals. The sloppy paired(s/p)gene shows a pair-ruleas well as a segment polarity expression pattern overlapping $w g$ but not en expressing cells. Considering its ability to activate $w g$ and repress en, Cadigan et al. (1994) proposed that s/p could be involved in the delineation of $e n$ and $w g$ competence domains. Naked ( $n k d)$ is a segment polarity gene whose lack of function produces multiple segmentation defects (see $e . g$. Jürgens et al., 1984). It shows a very complex pattern of expression. At the blastoderm stage, $n k d$ is almost ubiquitously expressed. High levels of Nkd are found in the 2-3 cells anterior to the En-stripe and low levels are found in cells just posterior to this stripe, whereas the cells expressing en show very scant Nkd levels. In loss-offunction $w g$ mutants, the expression of $n k d$ is initiated normally but is markedly reduced later. On the other hand, ectopic expression of $n k d$ mimics the phenotype of loss-of-function $w g$ mutants. Thus, $w g$ induces the expression of $n k d$, which itself acts as a repressor of $w g$ (Zeng et al., 2000).

Detailed genetic and molecular studies allowed the identification of segment polaritygenes and regulatory interactions underlying the inter-cellular dependence of enand $w g$ expressions. The gene en encodes a transcription factor that promotes the transcription of gene hedgehog (hh), whose product undergoes several post-translational modifications before being secreted. $\mathrm{Hh}$ secreted from the En-cell binds to its receptor Patched (Ptc) at the surface of neighbouring cells. The transduction of $\mathrm{Hh}$ signal ultimately results into the conversion of the Cubitus interruptus (Ci) protein into a transcriptional activator of gene $w g$ (this situation corresponds to the activation of Hh pathway). Cigene encodes a transcription factor that enables the expression of $\mathrm{Wg}$, a secreted glycoprotein, which binds to its receptor Frizzled (Fz) in the adjacent (En) cell. Consequently, the degradation of Armadillo (Arm) is prevented, leading to the activation of en (this situation corresponds to the activation of Wg pathway) (reviewed in Ingham and McMahon, 2001; Nybakken and Perrimon, 2002; Kalderon, 2002; Jiang, 2002).

Among the proteins that have been identified as components of the $\mathrm{Hh}$-signalling pathway, $\mathrm{Ci}$ is the only transcription factor. The native $\mathrm{Ci}$ is a large protein that contains three domains: a $\mathrm{N}$ terminal domain characteristic of transcriptional repressors, a zinc finger domain, and a C-domain typical of transcription activators (Alexandre et al.,1996). Ci exists in two distinct functional forms (depending on phosphorylation and on interactions with other factors): a full-length $\mathrm{Ci}-155$ form and a truncated form $\mathrm{Ci}$ 75 , which derives from $\mathrm{Ci}-155$ by proteolysis of its transcriptional activation domain. $\mathrm{Ci}-75$ acts as a transcriptional repressor, $\mathrm{Ci}[$ rep], whereas uncleaved $\mathrm{Ci}-155$ acts as a transcriptional activator, Ci[act], of Hh-responsive genes (Aza-Blanc et al., 1997). Although $c i$ is transcribed uniformly in all cells that are responsive to $\mathrm{Hh}$ producing the $\mathrm{Ci}[\mathrm{rep}]$, the $\mathrm{Ci}[\mathrm{act}]$ form accumulates specifically in cells adjacent to those secreting $\mathrm{Hh}$ (AzaBlanc et al., 1997; Motzny and Holmgren, 1995; Wang and Holmgren, 1999), suggesting that $\mathrm{Hh}$ acts by inhibiting the proteolytic cleavage of $\mathrm{Ci}-155$.

The Hh-signalling pathway comprises other components regulating the conversion of $\mathrm{Ci}$ into one of its two forms. These proteins include the membrane protein Smoothened (Smo), as well as the cytoplasmic proteins Protein kinase A (Pka), Costal-2 (Cos2), Suppressor-of-Fused ( $\mathrm{Su}(\mathrm{fu}))$ and Fused $(\mathrm{Fu})$. Smo is required to transduce the Hh signal. In the absence of Ptc, Smo activity is independent of the $\mathrm{Hh}$ ligand and constitutively activates the $\mathrm{Hh}$ signalling pathway. Thus, the binding of $\mathrm{Hh}$ to Ptc is thought to liberate Smo from repression by Ptc (Alcedo et al., 1996; Chen and Struhl, 1996; van den Heuvel and Ingham, 1996; Denef et al., 2000; Strutt et al., 2001; Martin et al., 2001). Pka inhibits Hhsignalling by phosphorylating Ci-155 (Lepage et al., 1995; Pan and Rubin, 1995; Jiang and Struhl, 1995; Li et al., 1999, Wang et al., 1999). Cos2 is a kinesin-related protein (Sisson et al., 1997), whose capacity to bind microtubules is reversed by $\mathrm{Hh}$-signalling (Robbins et al., 1997). It is required for proteolytic processing of Ci-155 (Wang and Holmgren, 2000). Su(fu) is not involved in the conversion of $\mathrm{Ci}-155$, but it appears to block the transport of $\mathrm{Ci}[\mathrm{act}]$ into the nucleus (Méthot and Basler, 2000; Wang et al., 2000). $\mathrm{Fu}$ is a serine-threonine protein kinase whose activity is necessary for some but not all levels of response to Hh (Alves et al., 1998; Ohlmeyer and Kalderon, 1998; Thérond etal., 1999). Fu is itself phosphorylated in an Hh-dependent manner (Thérond et al., 1993; Thérond et al., 1996) and phosphorylates Costal-2 (Nybakken et al., 2002). Apparently, Fu kinase opposes cytoplasmic retention of $\mathrm{Ci}[\mathrm{act}]$ by $\mathrm{Su}(\mathrm{Fu})$ (Méthot and Basler, 2000; Wang et al., 2000).

More precisely, the processing of $\mathrm{Ci}-155$ to generate $\mathrm{Ci}[$ rep] requires the sequential phosphorylation of $\mathrm{Ci}$ by three kinases. Pka phosphorylates multiple sites in the $\mathrm{C}$-terminal region of $\mathrm{Ci}$ and promotes further phosphorylation by Glycogen synthase kinase 3/Zeste white 3 (GSK3/Zw3) and caseine kinase I (CKI) at adjacent sites (Wang et al., 1999; Chen and Struhl, 1999; Price and Kalderon, 1999; Jia et al., 2002; Price and Kalderon, 2002). Pka plays a key role in this process because it targets full-length $\mathrm{Ci}-155$ for proteolysis into $\mathrm{Ci}[\mathrm{rep}]$ and also inhibits the conversion 
of Ci-155 into Ci[act] (Wang and Holmgren, 1999; Wang et al., 1999).

Several proteins have been identified as components of the Wg-signalling pathway (reviewed in Kalderon, 2002). One of these is Armadillo/beta-catenin, which is the effector of the Wgsignalling pathway. Other components of this pathway are Dishevelled (Dsh) and Zw3 (GSK3). Dsh is a positive regulator of Wg-signalling pathway activity (Li et al., 1999; Salic et al., 2000) and is required by the receptor complex to initiate the intra-cellular Wg-signalling cascade (Yanagawa et al.,1995; Axelrod et al., 1998; Boutros and Mlodzik, 1999; Rothbacher et al., 2000). Zw3 phosphorylates Arm, targeting it for degradation and thereby keeping the cellular pool of Arm low (Yost et al., 1996; Pai et al., 1997). In the absence of Wg-signal, Arm is continuously degraded (Cliffe et al., 2003). The binding of Wg-signal to its receptor Fz prevents the degradation of Arm, which is then stabilised and enters into the nucleus, where it binds the (constitutively expressed) transcription factor TCF and co-activates the transcription of target genes, including $n k d$, s/p and $e n$ (reviewed in Bienz and Clevers, 2003).

An important feature of the mutual inter-cellular regulatory interactions between $e n$ and $w g$ is the fact that these two genes remain active in adjacent rows of cells. This is so because the diffusions of secreted $\mathrm{Hh}$ and $\mathrm{Wg}$ are both limited. In the case of $\mathrm{Hh}$, one of the consequences of the Hh-signalling is to increase the transcription of $p t c$ in the adjacent $w g$ expressing cell ( $\mathrm{Wg}$-cell, for short). At high levels, Ptc can then sequester all the secreted $\mathrm{Hh}$, thereby impeding its diffusion towards more anterior cells (Chen and Struhl, 1996). With respect to Wg diffusion, it has been shown that its transport or stability is reduced in enexpressing cells (En-cell, for short) (Sanson et al., 1999).

In Drosophila embryos, secreted Wg can act upon the cell that secretes it (autocrinepathway) as well as upon neighbouring cells (paracrinepathway). These two pathways use the same receptor, $\mathrm{Fz}$, as well as the component Dsh of the Wg-signalling cascade. However, the paracrine pathway passes through Zw3 and then Arm, whereas the autocrine pathway seems to involve $\mathrm{Ci}$ (Hooper, 1994).

The Drosophilasegmentation process has stimulated a wealth of theoretical studies (Meinhardt, 1982, 1986; Bodnar, 1997; Reinitz et al., 1998; von Dassow et al., 2000; von Dassow and Odell, 2002; Houchmandzadeh et al., 2002; Albert and Othmer, 2003; Ingolia, 2004; Jaeger et al., 2004a,b; Alves and Dilão, 2006). Using a logical approach (cf. Materials and Methods section), we have previously developed qualitative models for the gap (Sánchez and Thieffry, 2001) and pair-rule (Sánchez and Thieffry, 2003) cross-regulatory modules. The present manuscript focuses on the analysis of the network of cross-regulations among the segment polarity genes. More specifically, it aims at better understanding how the expressions of en and $w g$ in juxtaposed cells, once activated by the pair-rulenetwork, become consolidated through inter-cellular interactions and various kinds of intra-cellular regulatory interactions. These events take place in a short period spanning embryonic stages 9-10 of CamposOrtega and Hartenstein (1985), approximately 3:40 - 5:20 h after egg laying.

The segment-polarity gene network has already been modelled in terms of ordinary differential (von Dassow et al., 2000; von Dassow and Odell, 2002; Ingolia, 2004) or Boolean (Albert and
Othmer, 2003) equations. These models present fundamental differences, regarding the regulatory elements and the regulatory interactions considered (see the supplementary figures, Figs. S1 to S3). As the data sets enlarge and more interactions become known, there have been refinements made to these models in the hopes of explaining the complete set of phenomena and delineating new experiments. The model of von Dassow and co-workers includes inhibitions of ptc and en by Ci[rep]. However, the background level of Ptc neither rises in the absence of Ci protein (Dominguez et al., 1996; Hepker et al., 1997; Méthot and Basler, 1999), nor disappears when Ci[rep] is over-expressed (Muller and Basler, 2000). Furthermore, ectopic expression of $c i$ does not repress the expression of $e n$ (Hepker et al., 1997). Von Dassow's model further encompasses an inhibition of $w g$ by Ci[rep], which is known to play a role later on during the specification of the cuticle formation, but not in the formation of the parasegment boundaries (Méthot and Basler, 1999; Gallet et al., 2000; Méthot and Basler, 2001). Von Dassow et al. consider that the Ci-155 protein obtained after translation of its mRNA is already the activatory form (i.e. Ci[act]), and they thus derive the repressor form (Ci[rep]) directly from $\mathrm{Ci}[$ act]. In contrast, in our model, we explicitly consider the three reported Ciproducts, Ci-155, Ci[act] and $\mathrm{Ci}[\mathrm{rep}]$, together with their differential regulation by the $\mathrm{Hh}$ pathway. This is important because it has been shown that $\mathrm{Wg}$ expressing cells respond to particular thresholds of $\mathrm{Hh}$ signal (Wang and Holmgren, 1999). Finally, the model of von Dassow et al. does not include s/p and $n k d$, which both contribute to restrict en and wg expressions (Cadigan et al., 1994; Zeng et al., 2000). Leaning on the preceding model, Ingolia (2004) also assumes that $w g$ expression is dependent on $\mathrm{Hh}$ signalling. However, Ingolia removed the repression of enby Ci[rep] (denoted CN), and introduced a mutual inhibition between $s / p$ and $e n$, with $s / p$ mediating the positive effect of en upon $h$ h. Next, Hh directly inhibits the conversion of $\mathrm{Ci}$ [act] (denoted $\mathrm{Cl}$ ) into $\mathrm{Ci}[$ rep], thus making Ptc implicit. Finally, cell division is incorporated into the model. Albert and Othmer (2003) considered the repression of ptc and $w g$ by Ci[rep], but neglected the requirement of $w g$ function for the maintenance of $s / p$ expression, as well as the repression of $s / p$ and $w g$ by $e n$. Similarly, the role of $n k d$ is not taken into account. Furthermore, their model does not recognize the autocrine and paracrine Wg-signalling pathways, thus impeding a proper analysis of the link between the $\mathrm{Wg}$ - and the Hh-signalling pathways. Finally, the use of a pure Boolean approach impeded the modelling of some subtle aspects of the behaviour of the segment polaritynetwork, such as the regulation of ptc. Since ptc is basally expressed in the $\mathrm{Wg}$-cell, there is certain low amount of $\mathrm{Hh}$ receptor present. After reception of $\mathrm{Hh}$ signal, the transcription of ptc increases significantly, thereby allowing the sequestration of all secreted $\mathrm{Hh}$ and preventing further anterior diffusion. Consequently, the gene $w g$ becomes transcribed only in the cell adjacent to the engrailedexpressing cell that secretes $\mathrm{Hh}$.

In this paper, we use the logical formalism developed by René Thomas and collaborators (Thomas, 1991; Thomas et al., 1995) to model the segment polarity module, focusing on the roles of the signalling pathways enabling the consolidation of En and $\mathrm{Wg}$ expression patterns beyond the syncytial stage. This logical approach (cf. Materials and Methods section) relies on the delineation of a regulatory graph, which represents the epistatic relationships inferred from genetic experiments. Subtler (e.g. 
synergic) relationships are encoded in terms of logical rules. The developmental properties derived from the resulting model are then systematically analysed for a strip of cells, representing a whole parasegment, and on different genetic backgrounds (e.g. gene knockouts, ectopic gene expressions, or combinations thereof).

\section{Results}

\section{Delineation of the segment polarity regulatory graph}

Our logical model of the segment polarity cross-regulatory module includes a series of simplifications, enabling the skeleton of the module to be more readily seen. In this simplified scheme, the Hh-signalling pathway is initiated by the binding of $\mathrm{Hh}$ to its receptor Ptc (Fig. 1A). As Smo merely connects the receptor and cytoplasmic components of the Hh-pathway, it is implicitly considered behind the arrow connecting Ptc and Pka. The cytoplasmic components are represented by Pka, which plays a key role in the conversion of $\mathrm{Ci}$, the target of the $\mathrm{Hh}$ signalling pathway. We further distinguish the native $\mathrm{Ci}-155$ form ( $\mathrm{Ci}$ in Fig. 1A), the functional activator form (Ci[act]), and the repressor form ( $\mathrm{Ci}[\mathrm{rep}])$. $\mathrm{Ci}[\mathrm{rep}]$ operates later in embryogenesis and during the development of imaginal discs, but it does not play important roles in the formation of the parasegment boundaries (Méthot and Basler, 1999). Although apparently not essential for wild type development, the repression of $h h$ by $\mathrm{Ci}[\mathrm{rep}]$ has been incorporated in the segment polarity regulatory graph because it might be detrimental when Hh-signalling is weakened (Gallet et al., 2000; Méthot and Basler, 2001). For sake of simplicity, the genes fuand Su(fu) are omitted because fu kinase activity is partially dispensable in wild type animals and entirely dispensable in animals lacking Su(fu)(Préat; 1992; Préat et al., 1993). The model thus assumes that Ci[act] translocates into the nucleus once it is formed. Finally, the role of Cos2 in the proteolytic processing of $\mathrm{Ci}-155$ is implicitly considered behind $\mathrm{Ci}-155$ phosphorylation by Pka.

In our model, Fz, the receptor of the $\mathrm{Wg}$-signal, together with Dsh represent the $\mathrm{Wg}$ signalling pathway. Although there are two Fz proteins ( $F z$ and Fz2) acting as Wg receptors, a single receptor of the $\mathrm{Wg}$ ligand is considered since the presence of either protein appears to be sufficient to transduce the $\mathrm{Wg}$ signal (Chen and Struhl, 1999). Dsh is assumed to play a role in both autocrine and paracrine $\mathrm{Wg}$ pathways. For simplification, Arm is omitted, as it is either destroyed or stably maintained depending on the activity of the $\mathrm{Wg}$-signalling pathway, so that its activity follows that of Fz and Dsh. This is different from the situation found for $\mathrm{Ci}-155$, the effector of the Hh-signalling pathway, which does not directly lead to functional Ci[act], but depends on phosphorylation by $\mathrm{Pka}$, which in turn depends on Hh signal. Zw3 function is implicitly represented by two different arcs: an activatory arc from Dsh upon En and a negative arc from Dsh upon Ci[rep].

The positive arc from Dsh towards

Fig. 1. The segment polarity network. (A) Cross-regulations between segment polarity regulatory factors. This regulatory graph explicitly encompasses the regulatory components $\mathrm{Wg}$, En, Hh, Slp, Nkd, Fz, Dsh, Pka, Ptc, as well as Ci-155 and its two functional forms Ci[act] and Ci[rep]. Normal and blunt arrows represent positive and negative interactions between these regulatory elements, respectively. Once Hh and $W g$ are excreted, they diffuse and interact with their respective receptors Ptc and Fz, which are present at the surface of the neighbouring cells. During normal development, this occurs between the cells flanking the para-segmental border (see text for further explanation). (B) Stripe encompassing six cells with inter-cellular connections through Wg and Hh signalling. These cells are numbered from 1 to 6 , with cell 3 denoting the cell just anterior to the border, cell 4 the cell just posterior to the border, whereas the other cells are linearly arranged along the anterior-posterior axis, according to their numbering. For more details see text. 
TABLE 1

\section{INTERACTIONS BETWEEN THE SEGMENT POLARITY REGULATORY PRODUCTS}

\begin{tabular}{|c|c|c|}
\hline Interactions & Main experimental observations & Bibliographical references \\
\hline $\mathrm{En} \rightarrow \mathrm{Hh}$ & In loss-of-function en mutants, $h h$ is not expressed & $1,2,3,4$ \\
\hline $\mathrm{En}-\mathrm{Wg}$ & Ectopic en expression suppresses wg expression & 1,5 \\
\hline $\mathrm{En} \dashv \mathrm{Ci}$ & Expression of en represses ci transcription & $1,6,7,8$ \\
\hline En $\dashv$ Ptc & Ptc protein is not detected in cells expressing en & 9 \\
\hline En $\dashv$ SIp & Ectopic en expression suppresses slp expression & 1,10 \\
\hline En $\dashv$ Nkd & $n k d$ expression is strongly reduced in en-expressing cells & Novel interaction derived from published data (see text for details) \\
\hline $\mathrm{Wg} \rightarrow \mathrm{Fz}$ & The binding of secreted $\mathrm{Wg}$ to its receptor Fz causes its activation & 11,12 \\
\hline Slp $\rightarrow$ Wg & All the cells expressing $w g$ in loss-of-function $p t c$ mutants require functional $s / p$ for $w g$ expression & 13 \\
\hline Slp $\dashv$ En & In loss-of-function s/p mutants, en is ectopically expressed: ectopic s/p expression represses en & 13 \\
\hline $\mathrm{Nkd}-\dashv \mathrm{Wg}$ & Ectopic $n k d$ expression results in decreasing $w g$ expression & 14 \\
\hline Nkd $\dashv$ En & In $n k d^{-}$embyos, en is de-repressed & $5,15,16,17$ \\
\hline $\mathrm{Hh} \dashv \mathrm{Ptc}$ & The binding of secreted $\mathrm{Hh}$ to its receptor Ptc causes its inactivation & 9,15 \\
\hline Ptc $\rightarrow$ Pka & Ptc inhibits Smo that, in turn, inhibits Pka & Cf. Introduction \\
\hline Pka $\dashv \mathrm{Ci}[\mathrm{act}]$ & Low levels of phosphorylation of $\mathrm{Ci}-155$ by Pka prevents the formation of $\mathrm{Ci}$ [act] & 18 \\
\hline Pka $\rightarrow$ Ci[rep] & Conversion of $\mathrm{Ci}$ into $\mathrm{Ci}[\mathrm{rep}]$ form requires $\mathrm{Pka}$ activity & 18 \\
\hline $\mathrm{Ci}[\mathrm{act}] \rightarrow \mathrm{Wg}$ & In loss-of-function ci mutants, wg expression fades, whereas ectopic ci activates $w g$ & 16,19 \\
\hline $\mathrm{Ci}[\mathrm{act}] \rightarrow \mathrm{Ptc}$ & In loss-of-function ci mutants, ptc expression fades, whereas ectopic ci activates ptc & 16,19 \\
\hline Ci[rep] $\dashv \mathrm{Hh}$ & In ci mutant clones, there is activation of $h h$ & 6,7 \\
\hline $\mathrm{Fz} \rightarrow \mathrm{Dsh}$ & Dsh serves as a sensor of Fz activity and is required for Wg-signalling & $20,21,22,23,24$ \\
\hline Dsh $\rightarrow$ En & Dsh inhibits Zw3, the inhibitor of Arm that activates gene en & Cf. Introduction \\
\hline Dsh $\rightarrow$ Nkd & In $w g^{-}$embryos, $n k d$ expression decays, and ectopic $w g$ expression enhances $n k d$ expression & 14 \\
\hline Dsh $\rightarrow$ Ci[act] & Dsh participates in the autocrine $\mathrm{Wg}$-signalling pathway via $\mathrm{Ci}$ & 25 \\
\hline Dsh $\dashv$ Ci[rep] & Dsh inhibits Zw3, which participates in the proteolysis of Ci-155 into Ci-75 & Cf. Introduction \\
\hline
\end{tabular}

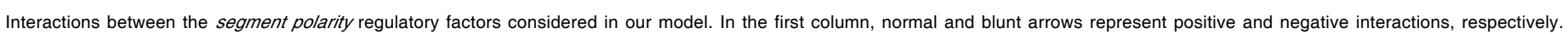

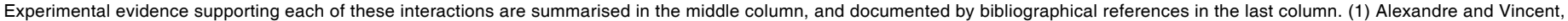

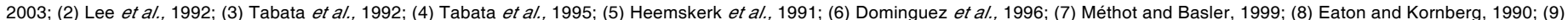

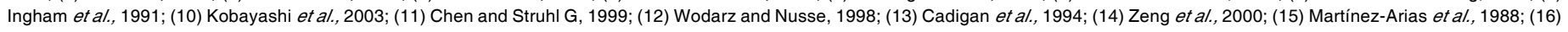

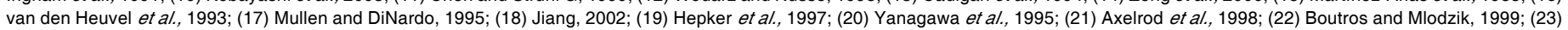
Rothbacher et al., 2000; (24) Noordermeer et al., 1994; (25) Hooper, 1994.

Nkd implements the activatory effect of $\mathrm{Wg}$ upon $n k d$ expression (Zeng et al., 2000). We also consider direct repression of wg (Zeng et al., 2000) and en by Nkd (Martínez-Arias et al., 1988; Heemskerk et al., 1991; van den Heuvel et al., 1993; Mullen and DiNardo, 1995). In fact, the gene $n k d$ is initially expressed in the cells where enexpression is also initiated, yet the En-cell shows later scant Nkd levels (Zeng et al., 2000). We thus assume that $e n$ acts as a repressor of $n k d$. Consequently, in our model, we consider mutual negative interactions between $e n$ and $s / p$, as well as between $e n$ and $n k d$.

During the consolidation of the mutual dependence of enand wg expressions, en does not appear to be able to maintain its own expression alone. In contrast, the action of Wg (from the Wg-cell) upon the En-cell is necessary and sufficient to maintain en expression (Heemskerk et al., 1991). Yet, we consider en auto-regulation in our model to encompass the transition between the formation of the parasegmental boundaries and the formation of the final segmental boundaries, which depends on en-autoregulation (when en expression becomes independent of $\mathrm{Wg}$-signalling). Once the parasegment boundary is formed, en, initially expressed in one single cell (cell 4 in our model), becomes expressed into 2-3 cells following cell rearrangement and division, so that the daughter cells inherit the auto-regulatory state of $e n$.

In brief, although simplified, the resulting regulatory graph preserves the main regulatory relationships between selected components of the segment polarity network (see Fig. 1A).
These regulatory relationships have been derived from the published phenotypes of segment polaritymutants. A listing of experimental results backing these interactions is provided in Table 1, together with bibliographical references.

\section{Parameterisation of the segment polarity regulatory graph}

For parsimony, we have assumed that most segment polarity genes (and then their products) have a single functional threshold. However, Wg, Ptc, Ci[act], Pka, and Nkd, are each assumed to have two significantly distinct functional levels (i.e. the corresponding logical variables can take three different values: 0, 1 and 2).

In ptcmutants, the Wg-domain broadens (Ingham etal., 1991). $\mathrm{Wg}$ itself modulates this expansion since in double ptc and $\mathrm{wg}$ loss-of-function mutants, wg expression disappears, remaining only in occasional cells (Hooper, 1994; Ingham and Hidalgo, 1993; Bejsovec and Wieschaus, 1993; Yoffe et al., 1995). Thus, wgup-regulates its own expression by an $\mathrm{Hh}$-independent mechanism (autocrine $w g$ function). In $p t c w g^{t s}$ double mutants with low levels of functional $\mathrm{Wg}$, large clusters of $w g$ expressing cells replace the small clusters seen in ptc $w g$ double mutants with no functional Wg protein. Importantly, these Wg-cell clusters are not adjacent to cells expressing en (Yoffe et al., 1995). Thus, the cells expressing $w g$ produce levels of $\mathrm{Wg}$ sufficient to activate the autocrine $w g$ function, but insufficient to induce expression of $e n$ in adjacent cells, i.e. to activate the paracrine $w g$ function. Consequently, we consider that the amount of secreted $\mathrm{Wg}$ 
protein needed to induce the autocrine Wg-pathway in the Wg-cell is lower than that needed to activate the paracrine Wg-pathway in the En-cell ( $\mathrm{Wg} \geq 1$ for autocrine function; $\mathrm{Wg}=2$ for paracrine function).

The receptor $\mathrm{Fz}$ is considered to be active $(F z=1)$ when it is bound to its ligand, the secreted Wg protein. Dsh level follows that of Fz, since Dsh transduces Wg signal towards cytoplasmic components. Indeed, loss-of-function mutations of fzor dshshow similar altered segment polarity phenotypes.

ptcis expressed at a basal level in the cells that do not express $e n$. We consider that the receptor Ptc is active when it is available in its free form, i.e. not bound to $\mathrm{Hh}$. Ptc is assumed to be inactive (Ptc $=0)$ when it is bound to $\mathrm{Hh}$. The transcription of ptc is increased when the $\mathrm{Wg}$-cell responds to the $\mathrm{Hh}$ signal. Two functional levels are thus introduced for free Ptc, which correspond to basal expression (Ptc $=1$ ) and to transcriptional activation (Ptc = 2).

$P k a$ is considered to be active $(P k a \neq 0)$ when it is able to phosphorylate $\mathrm{Ci}-155$. As Pka activation depends on free Ptc level, we also consider two different functional levels for Pka, correlated with those of Ptc.

We further assume that the presence of the $\mathrm{Ci}-155$ protein is totally dependent on whether En is present. The levels of $\mathrm{Ci}$ [act] and $\mathrm{Ci}[$ rep] depend on the levels of the factors controlling the conversion of $\mathrm{Ci}-155$. In this respect, we assume that $\mathrm{Ci}$ [act] has two functional levels, matched by Wg: when $\mathrm{Ci}[$ act] reaches the value 1 , the gene $w g$ is expressed at an intermediate level $(\mathrm{Wg}=1)$, whereas, when $\mathrm{Ci}[\mathrm{act}]$ reaches the value 2 , the gene $\mathrm{wg}$ is expressed at a higher rate $(\mathrm{Wg}=2)$. Furthermore, we assume

TABLE 2

LOGICAL PARAMETERS DEFINING THE EFFECT OF REGULATORY ELEMENTS IN AND BETWEEN THE ANTERIOR AND POSTERIOR CELLS FLANKING THE PARA-SEGMENTAL BOUNDARY

\begin{tabular}{|c|c|c|}
\hline Network element & Maximal variable value & Logical parameter values \\
\hline $\mathrm{Wg}$ & 2 & $\begin{array}{l}\mathrm{K}_{\mathrm{Wg}_{\mathrm{g}}}(\{\mathrm{Slp}, 1\},\{\mathrm{Ci}[\mathrm{act}], 1\})=1 \\
\mathrm{~K}_{\mathrm{Wg}}(\{\mathrm{Slp}, 1\},\{\mathrm{Ci}[\mathrm{act}], 2\})=2 \\
\mathrm{~K}_{\mathrm{Wg}_{\mathrm{g}}}(\{\mathrm{Slp}, 1\},\{\mathrm{Ci}[\mathrm{act}], 2\},\{\mathrm{Nkd}, 2\})=2\end{array}$ \\
\hline $\mathrm{Fz}$ & 1 & $\mathrm{~K}_{\mathrm{Fz}}(\{\mathrm{Wg},[1,2]\})=1$ \\
\hline Dsh & 1 & $\mathrm{~K}_{\mathrm{Dsh}}(\{\mathrm{Fz}, 1\})=1$ \\
\hline SIp & 1 & $\mathrm{~K}_{\mathrm{SIp}}(\{\mathrm{Dsh}, 1\})=1$ \\
\hline Nkd & 2 & $\begin{array}{l}\mathrm{K}_{\mathrm{Nkd}}(\varnothing)=1 \\
\mathrm{~K}_{\mathrm{Nkd}}(\{\mathrm{Dsh}, 1\})=2\end{array}$ \\
\hline En & 1 & $\begin{array}{l}\mathrm{K}_{\mathrm{En}}(\{\text { Dsh, } 1\})=1 \\
\mathrm{~K}_{\mathrm{En}}(\{\text { Dsh, } 1\},\{\mathrm{En}, 1\})=1 \\
\mathrm{~K}_{\mathrm{En}}(\{\text { Dsh, } 1\},\{\mathrm{Nkd},[1,2]\})=1 \\
\mathrm{~K}_{\mathrm{En}}(\{\text { Dsh, } 1\},\{\mathrm{En}, 1\},\{\mathrm{Nkd},[1,2]\})=1\end{array}$ \\
\hline $\mathrm{Hh}$ & 1 & $\mathrm{~K}_{\mathrm{Hh}}(\{\mathrm{En}, 1\})=1$ \\
\hline Ptc & 2 & $\begin{array}{l}\mathrm{K}_{\text {Ptc }}(\varnothing)=1 \\
\mathrm{~K}_{\mathrm{pPtc}}(\{\mathrm{Ci}[\mathrm{act}],[1,2]\})=2\end{array}$ \\
\hline Pka & 2 & $\mathrm{~K}_{\mathrm{Pka}}(\{\mathrm{Ptc}, 1\})=2$ \\
\hline $\mathrm{Ci}$ & 1 & $\mathrm{~K}_{\mathrm{Ci}}(\varnothing)=1$ \\
\hline $\mathrm{Ci}[\mathrm{act}]$ & 2 & $\begin{array}{l}\mathrm{K}_{\mathrm{Ci}[\mathrm{act}]}(\{\mathrm{Ci}, 1\})=1 \\
\mathrm{~K}_{\mathrm{Ci}[\mathrm{act}]}(\{\mathrm{Ci}, 1\},\{\text { Dsh, } 1\},\{\text { Pka, }[1,2]\})=1 \\
\left.\mathrm{~K}_{\mathrm{C} \text { [iact }]}\{\mathrm{Ci}, 1\},\{\text { Dsh, } 1\}\right)=2\end{array}$ \\
\hline Ci[rep] & 1 & $\mathrm{~K}_{\text {Ci[act] }}(\{\mathrm{Ci}, 1\},\{\mathrm{Pka}, 2\})=1$ \\
\hline
\end{tabular}

Interactions are denoted by the name of their source node, together with the level(s) for which they are operative. The value of a parameter defines the effect of a given combination of interactions (set in parentheses) operating on a given regulatory element (sub-index of the parameter). An empty set $(\phi)$ denotes a basal functional level. $\mathrm{K}_{\mathrm{Wg}}(\{\mathrm{SIp}, 1\},\{\mathrm{Ci}[\mathrm{act}], 1\})$ denotes the target value of $\mathrm{Wg}$ in the presence of Slp and Ci[act] (both at level 1) but in the absence of Nkd. Note that only the non-zero parameters are listed (i.e. all other combinations of inputs on a given gene drive it to the level 0 per default). that both the autocrine and paracrine $\mathrm{Wg}$-pathways are required to reach the highest level of $\mathrm{Ci}[\mathrm{act}](\mathrm{Ci}[\mathrm{act}]=2)$. Note that, in $\cos 2$ mutants, the ectopic activation of $w g$ is significantly delayed with respect to the increased activation of ptcin the Wg-cell (Forbes et al., 1993), suggesting that these genes may require a different amount of $\mathrm{Ci}[\mathrm{act}]$ for their activation.

The phosphorylation of $\mathrm{Ci}-155$ by Pka plays a dual role. It targets the proteolysis of $\mathrm{Ci}-155$ to form $\mathrm{Ci}[$ rep], and it inhibits the conversion of $\mathrm{Ci}-155$ into $\mathrm{Ci}[\mathrm{act}]$. The pathway chosen by $\mathrm{Ci}-155$ depends on its degree of phosphorylation: a higher level prompts the conversion of $\mathrm{Ci}-155$ into $\mathrm{Ci}[$ rep], whereas the lack (or lower level) of phosphorylation causes its transformation into Ci[act] (Wang et al., 1999; Price and Kalderon, 1999; Jia et al., 2002; Price and Kalderon, 2002; Chen et al., 1999). Alteration of individual Pka-phosporylation sites on $\mathrm{Ci}-155$ abolishes its conversion into $\mathrm{Ci}[$ rep] but does not transform it into $\mathrm{Ci}[$ act]. Alteration at multiple sites not only inhibits conversion of Ci155 into Ci[rep] but also promotes its transformation into Ci[act] (Wang et al., 1999). This further justifies the distinction between two significant functional levels for $\mathrm{Pka}$, with high levels $(\mathrm{Pka}=2)$ stimulating the formation of $\mathrm{Ci}[$ rep] (phosphorylation), whereas medium or high levels $(\mathrm{Pka} \geq 1)$ prevent the conversion of $\mathrm{Ci}-155$ into $\mathrm{Ci}$ [act] (residual phosphorylation of $\mathrm{Ci}-155)$.

Finally, we also consider two functional thresholds for Nkd. Medium or high levels ( $N k d \geq 1)$ enable the repression of $e n$, whereas highest levels $(\mathrm{Nkd}=2)$ are needed to further repress $w g$. Indeed, high levels of Nkd are found anteriorly to the En-stripe (in cells 2 and 3 of our model, see Fig. 1B), whereas low levels are detected in the cells posterior to that stripe (cells 5 and 6 of our model). Although high levels of Nkd are expressed in cells 2 and 3 , repression of $w g$ by Nkd only occurs in cell 2. Consequently, we assume that the activation of Hh-pathway in cell 3 overcomes the repression effect of $\mathrm{Nkd}$ upon $w g$, leading to high levels of $\mathrm{Ci}$ [act] $(\mathrm{Ci}[\mathrm{act}]=2)$. In contrast, in cell 2, the Hh-pathway is not activated due to the lack of $\mathrm{Hh}$ input. Consequently, cell 2 cannot produce much $\mathrm{Ci}[$ act], and $\mathrm{Nkd}$ can repress $\mathrm{Wg}$. In cell 4 , both enand $n k d$ are initially activated. By assuming that the pair-rule signal can overcome the repression of $e n$ by Nkd, En can repress $n k d$ in this cell, ultimately leading to the fading out of Nkd (the detected scant levels of Nkd are considered as negligible).

On the basis of the regulatory interactions and activity levels just delineated, we can now define the logical rules (or logical parameters) enabling each regulatory component to reach significant expression levels. Table 2 lists all the non-zero parameter values used in our simulations. This set of values has been progressively specified by comparing simulation results with published experimental data, describing wild-type as well as mutant phenotypes, and applying simplicity criteria (i.e. selecting the lowest parameter value) whenever different values are compatible with available data.

To delineate the essential (wild type and mutant) properties of the segmentpolaritynetwork in the formation of the parasegmental boundaries, it suffices to consider six cells representing the three classes of cells (or regions, since one cell of the model might represent several cells at some point during the differentiation process) within the putative parasegment, which are determined by the expression pattern of the pair-rule genes (represented in the model by SIp, together with proper initial patterns for Wg, En, and SIp). These classes of cells are defined by their capacity to 
express either en or wg under the action of the pair-rule signal. Cells 1 and 6 represent cells lacking both enand wgexpressions. Cells 2 and 3 represent cells initially expressing wg. Cells 4 and 5 represent cells initially expressing en. However, only the juxtaposed cells 3 and 4 (where the parasegmental boundary will be formed) maintain $w g$ and en expression. Therefore, the intracellular network just described has been iterated six times to represent the different gene expression domains flanking each parasegmental border. The cells are numbered from 1 to 6 , with cell 3 denoting the cell just anterior to the border, cell 4 the cell just posterior to the border, whereas the other cells are linearly arranged along the anterior-posterior axis, according to their numbering (Fig. 1B). Altogether, these six cells represent a full parasegment, traversed by the future border at its middle. Communications between these cells occur through $\mathrm{Hh}$ and $\mathrm{Wg}$ signals, and in the wild-type case, we assume that these intercellular interactions are restricted to neighbouring cells. (However, this restriction can be released to account for particular situations, as, for example, to simulate specific perturbations, cf. Discussion). As we shall see, the logical parameters allow us to qualitatively recover all documented mutant phenotypes, including expanded $w g$ or en expression domains combined with ectopic en or $w g$ expression stripes.

\section{Dynamics of the segment polarity network}

On the basis of the regulatory graph delineated in Fig. 1A and implemented with logical parameter values (cf. Table 2), we can show that a given cell can reach five different stable states depending on inputs or initial conditions (cf. Table A1 in Appendix). One of these stable states accounts for the normal Wg expressing region, with Wg, Fz, Dsh, Slp, Nkd, Ci and Ci[act] all expressed at their maximal levels, whereas the remaining factors are OFF. Another stable state represents the normal En expressing region, with $\mathrm{En}$ and $\mathrm{Hh} \mathrm{ON}$, but also high $\mathrm{Fz}$ and Dsh expressed, due to $\mathrm{Wg}$ input from the anterior cell (all the other components being OFF). The three other asymptotical states are devoid of $\mathrm{Wg}$, En and $\mathrm{Hh}$ expressions, but vary in terms of the other component expressions, depending on input signals (cf. supplementary material for more details).

Considering now a strip of six cells connected through Wg and $\mathrm{Hh}$ signalling between neighbouring cells (Fig. 1B), we obtain 65 stable configurations of the five states just mentioned. Some of these stable states correspond to symmetrical situations. Counting pairs of symmetrical states only once, we still obtain 29 different stable configurations for the six connected cells (cf. supplementary material). However, most of these configurations may not be reachable from realistic initial conditions.

To delineate which stable configurations are indeed reachable from plausible initial conditions, we have translated our logical models into discrete Petri nets and applied the reachability analysis tool of INA (cf. Materials and Methods section). In the wild-type situation, the initial conditions in each cell result from the activity of the pair-rule module. We have considered that $\mathrm{Wg}$ and SIp could be initially expressed in a few cells just anteriorly to the forming parasegmental border (cells 2 and 3 in our model encompassing 6 cells). Similarly, we have considered that En and $\mathrm{Hh}$ could be initially expressed in both cells 4 and 5 . As a consequence, Pka, Ptc, Nkd and $\mathrm{Ci}$ are initially expressed in all cells, excepting cell 4 and 5 , due to the presence of En. Initially expressed in a ubiquitous manner (see Introduction), Nkd is considered to be active in all cells at the initial state, although it becomes quickly repressed in cell 4 by En.

To further simplify the dynamical analysis, we have taken into account generic differences in the speed of logical transitions, assigning a low priority to all transitions corresponding to de novo protein syntheses (cf. Materials and Methods). Fig. 2 shows the initial state used for our strip of six cells, together with the two significant stable configurations reachable from these initial conditions.

The first configuration corresponds to the wild type situation, wherein each of the cells flanking the forming segmental border expresses a specific combination of functional regulatory products. The cell located just anteriorly to the forming segmental border (cell 3) is characterised by the expression of $\mathrm{wg}, \mathrm{s} / \mathrm{p}, \mathrm{nkd}$ and $c i$, the presence of $\mathrm{Ci}[\mathrm{act}]$, as well as of Fz and Dsh, both participating in the autocrine $\mathrm{Wg}$ pathway. The remaining segment polarity genes/products are inactive. Note that after the reception of the $\mathrm{Hh}$ signal by the $\mathrm{Wg}$-cell, there is no active Ptc at the stable state because all the Ptc product (including that from newly transcribed $p t c$ ) is bound to the secreted $\mathrm{Hh}$, thereby preventing $\mathrm{Hh}$ diffusion towards more anterior cells. In contrast, the cell located just posteriorly to the forming border (cell 4) expresses genes en and $h h$, secretes $\mathrm{Hh}$, with both Fz (the Wgreceptor) and Dsh activated by $\mathrm{Wg}$ diffusing from the neighbouring anterior cell (paracrine Wg-pathway), whereas the remaining segmentpolaritygenes/products are inactive. The four other cells considered (cells 1, 2, 5 and 6) reach a state devoid of En and Wg expression, even when we considered the possibility of a significant initial expression of En (in cell 2) or Wg (in cell 5).

However, from realistic initial conditions, the system can also reach another stable state, which is characterised by the loss of $\mathrm{Wg}$ and En expression in the whole segment. All cells are then trapped in the same stable state, with Nkd moderately expressed (at its intermediary level 1), and Ci, Ci[rep], Pka and Ptc all highly expressed.

On the basis of these results, we can now delineate the conditions required for the segment polaritynetwork to reach the wild type stable state. Firstly, both autocrine and paracrine Wgpathways need to be functional. This means that the maximal functional level of $w g$ expression in the Wg-cell can only be attained when this cell receives auto-secreted $\mathrm{Wg}$ and simultaneously receives $\mathrm{Hh}$ secreted by the adjacent En-cell, as a consequence of paracrine $\mathrm{Wg}$ signalling on this cell, which requires a high $\mathrm{Wg}$ level $(\mathrm{Wg}=2)$ (cf. the section devoted to the Analysis of genetic perturbation, in particular the analysis of $w g$ partial loss-of-function). Secondly, as schematised in Fig. 2, the pair-rule inputs upon enand $w g$ need to last long enough to enable full activation of both $\mathrm{Wg}$ - and $\mathrm{Hh}$-signalling pathways. If the pairrule signal fades away before the two signalling pathways are fully functional, the segment polarity system reaches a final state characterised by the absence of expression of $e n$ and $w g$, and consequently the parasegment boundary cannot be formed.

\section{Feedback circuit analysis}

The network described into Fig. 1A encompasses 20 intracellular regulatory circuits, involving from one to eight regulatory components. Using a novel algorithm to compute the corresponding functionality domains (cf. Materials and Methods and Naldi et 


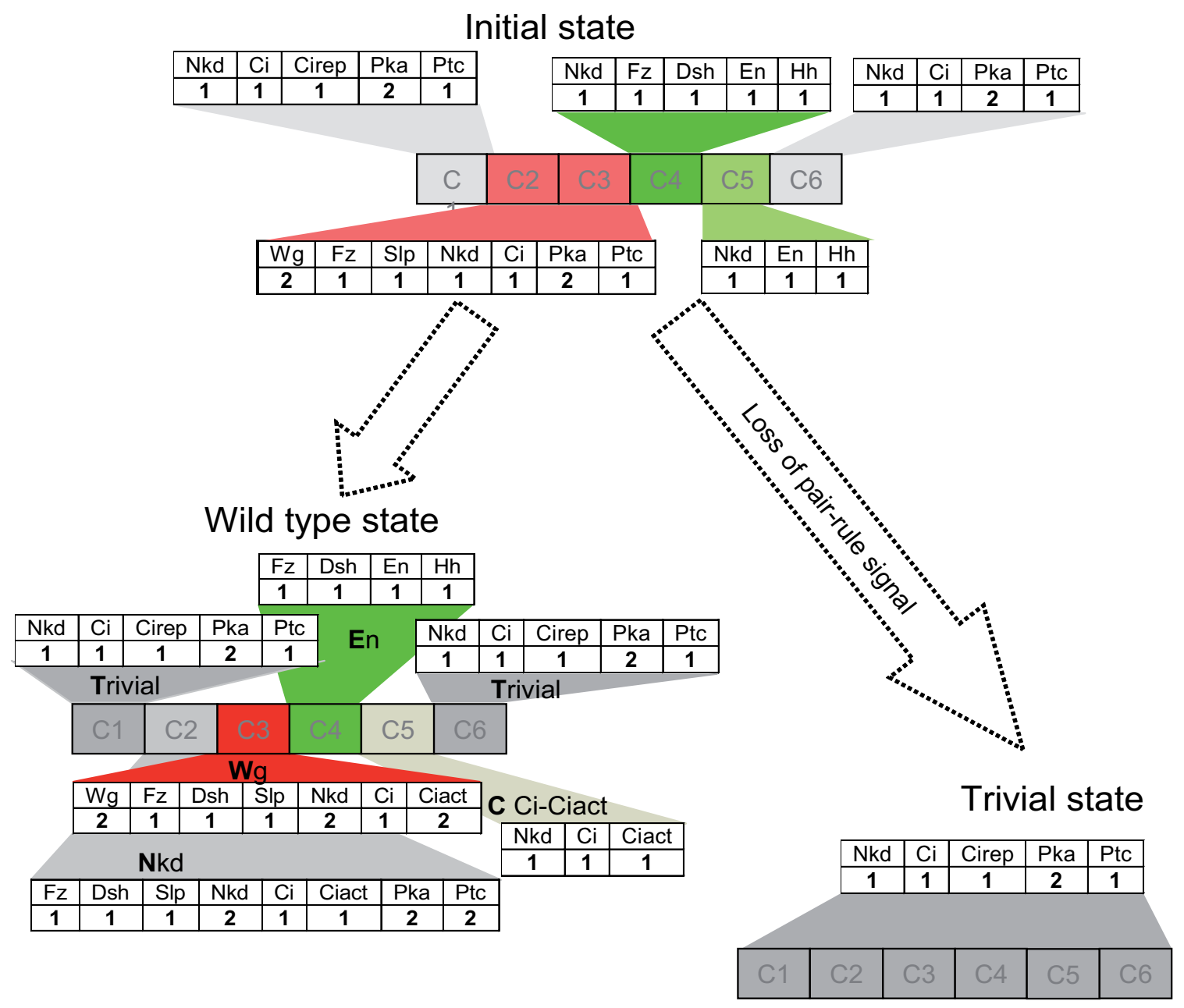

Fig. 2. Simulation of the wild-type dynamics of the segment polarity network. C1 to C6 represent the six cells of Fig. 1B. The vectors with gene names and numbers describe the levels of activated regulatory factors in the different cells, the rest of the genes being OFF. The initial state is provided by the expression of the pair-rule module, in terms of En, Wg and SIp levels, plus ubiquitous expression of $\mathrm{nkd}$. Fz is further activated in the three cells (C2-4) receiving Wg signal, whereas Ptc, Pka and Ci are activated in all cells devoid of En. Here, we consider fuzzy initial expression patterns for En and Wg. each spanning over two cells, a situation which nevertheless normally leads to crisper (one cellwide) expression domains. For these initial conditions, the system can follow multiple trajectories, leading to two significant stable states: a stable state qualitatively matching the wildtype pattern, as well as a trivial state lacking both Wg and En across the whole segment. This trivial state is reached when the initial En and Wg pattern (set by the pair-rule module) fades before the locking of the inter-cellular circuit involving Hh and Wg signalling pathways (cf. Fig. 3).

al., 2007), we found that only four of these circuits are functional for the parameter values selected and for specific constraints on the values of input components:

- The positive (cross-inhibitory) circuit En-Slp is functional in the presence of Dsh. This circuit ensures mutual exclusion between En and SIp expressions and enables the generation of two stable states in the presence of Wg signalling, with En ON and SIp OFF, or the opposite configuration. In absence of Dsh, both En and SIp are switched OFF.

- The positive circuit Dsh-Ci[act]-Wg-Fz (involving two different thresholds of $\mathrm{Ci}[\mathrm{act}])$ is functional in the absence of En, and consequently when the Hh-pathway is not induced, and in the presence of SIp and $\mathrm{Ci}$. This circuit corresponds to the action of $\mathrm{Wg}$ autocrine loop.

- The positive circuit Dsh-Slp-Wg-Fz is also functional in the absence of En (in the same cell) and consequently when the Hhpathway is not induced, and in the presence of $\mathrm{Ci}$ [act]. This circuit implies a role of Slp in the maintenance of $\mathrm{Wg}$. Together with the preceding positive circuit (also involving Dsh, Wg and $\mathrm{Fz}$, but $\mathrm{Ci}[\mathrm{act}]$ instead of SIp), this circuit enables the generation of three alternative stable states when $\mathrm{En}$ is absent, characterised with low, moderate or high levels of Wg activity, respectively.

- Finally, the negative circuit Wg-Fz-Dsh-Nkd is functional in the absence of En (in the same cell), but functions only in the presence of SIp and of moderate levels of Ci[act] (Ci[act] $=1)$, as well as for low or moderate $\mathrm{Wg}$ input $(\mathrm{Wg} \leq 1)$. However, at the cellular level, these conditions are simultaneously met only in cell 2 in our six-cell model, and this cell is normally flanked by a cell (cell 3) expressing a high level of Wg. Consequently, this circuit cannot generate oscillatory gene expression in the wild-type situation. However, wg-repression by Nkd plays a crucial role in cell 2 by antagonising the autocrine-Wg pathway.

Once we connect neighbouring cells through $\mathrm{Wg}$ and $\mathrm{Hh}$ signalling pathways, we obtain 265 additional inter-cellular circuits (counting symmetrical circuits only once). However, only one of these circuits is functional, involving $\mathrm{Hh}, \mathrm{Fz}$, Dsh and $\mathrm{En}$ in one cell, and Ptc, Pka, $\mathrm{Ci}[$ act] and $\mathrm{Wg}$ in the neighbouring cell. This positive inter-cellular circuit thus involves both $\mathrm{Wg}$ and $\mathrm{Hh}$ signalling pathways (see Fig. 3). In the wild-type case, the functionality constraints (cf. supplementary material) are met only in the pair of cells flanking the forming segmental border (cells 3 and 4 in our model), leading to maintenance of $\mathrm{Wg}$ versus $\mathrm{En}$ 
expressing states in these neighbouring cells. The role of this circuit consists thus in forcing the right combination of stable states at the right location to specify the position of the forming segmental border.

\section{Analysis of genetic perturbations}

To test the consistency and the qualitative robustness of our model, we have simulated a series of perturbations of the segment polarity module. Single and double loss-of-function mutations were simulated, as well as various ectopic expression experiments, and combination thereof (cf. the Materials and Methods section and supplementary material). Selected examples are presented in what follows and listed in Table 3, together with corroborating references.

In loss-of-function mutants of genes $w g$, en, hhand ci, a unique stable state is attained, lacking both $w g$ and enexpressions (in the case of $\mathrm{Ci}$, there is neither $\mathrm{Ci}[\mathrm{rep}]$ ), in agreement with published experimental data (cf. references in Table 3).

In loss-of-function ptcmutants, the system encompasses up to 64 stable states, down to 36 after discarding the symmetrical ones. Using two priority classes and INA (cf. Materials and Methods section), only two stable states are reached. In both states, we have an anterior expansion of Wg expression, together with a posterior expansion of $\mathrm{Ci}[\mathrm{act}]$. In one of these states, we further observe an ectopic expression of En in cell 1, in agreement with published results (Ingham et al., 1991).

In loss-of-function $n k d$ mutants, the system has up to 106 non- symmetrical stable patterns, combining four among the five stable cellular states (that characterised by Nkd expression is lacking, see Table A1 in Appendix), and a novel cellular state characterised by medium levels of $\mathrm{Wg}$ and $\mathrm{Ci}[\mathrm{Act}]$, together with active $\mathrm{Wg}$ and Hh signalling components: Fz, Dsh, Slp, Ci, Pka and Ptc (cf. Table 3). This large set of stable states includes a state corresponding to the observed experimental situation. The Wg-stripe expands anteriorly, whereas the En-stripe expands posteriorly and induces $w g$ in the adjacent posterior cell (Martínez-Arias et al., 1988; van den Heuvel et al., 1993). However, this state is difficult (if not impossible) to reach from realistic initial conditions, even using the priorities mentioned above. Tentatively, this discrepancy results from an increased diffusion of $\mathrm{Wg}$, which appears to be restricted by Nkd in vivo(Zeng et al., 2000; Moline et al., 1999). To test this hypothesis, we have analysed a variant of our model allowing diffusion of $\mathrm{Wg}$ towards posterior cells. In this situation, the system can indeed easily reach a state corresponding to the expected pattern (cf. Table 3 and supplementary material). Notice that the complete simulation of these mutants could not be performed in a model based on four instead of six cells, since the ectopic expression of $\mathrm{Wg}$ that characterises these mutants occurs in cell 6, which is adjacent and posterior to the cell 5, which is ectopically expressing En.

The double loss-of-function ptc; hh mutant shows the same phenotype as the loss-of-function ptc mutant, where $w g$ and en remain active, in contrast with the single loss-of-function $h h$ situation, where $w g$ and $e n$ are both inactivated. This matches the

TABLE 3

\section{MOST SIGNIFICANT STABLE STATES FOR THE WILD-TYPE AND FOR KNOWN MUTANTS}

Genetic background

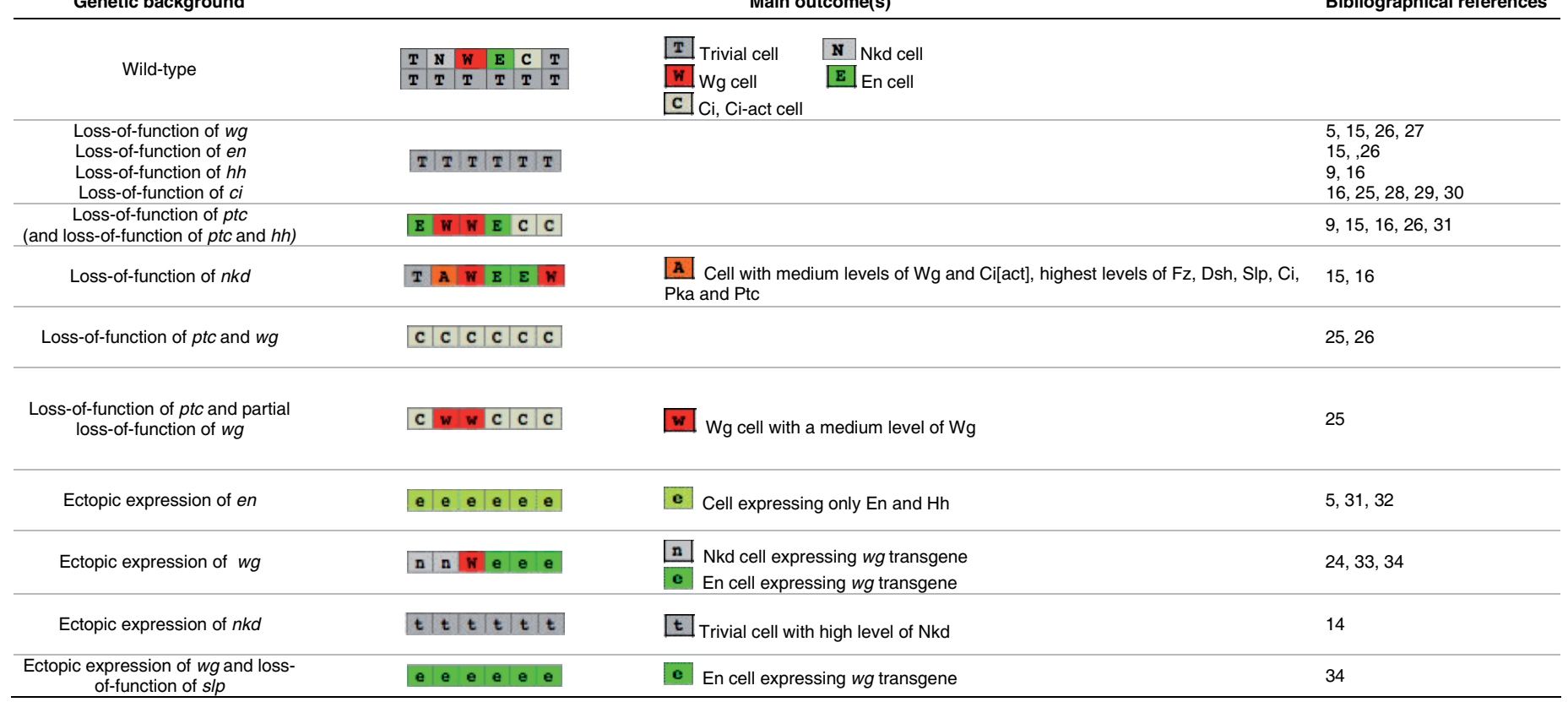

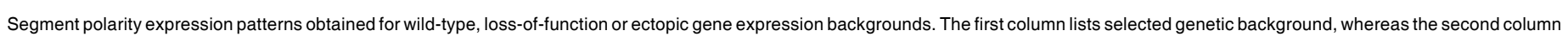

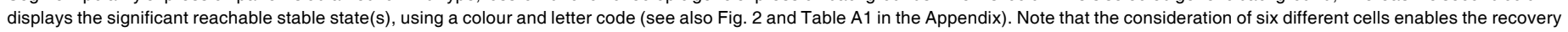

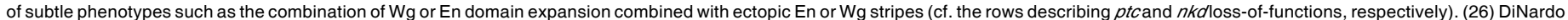

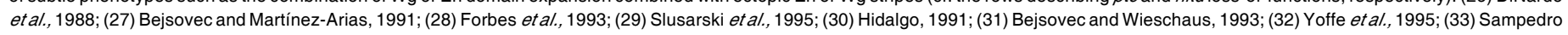
et al., 1993; (34) Noordermeer et al., 1995; for the rest of references see footnote to Table 1. (See Supplementary material for a complete description of simulation results). 

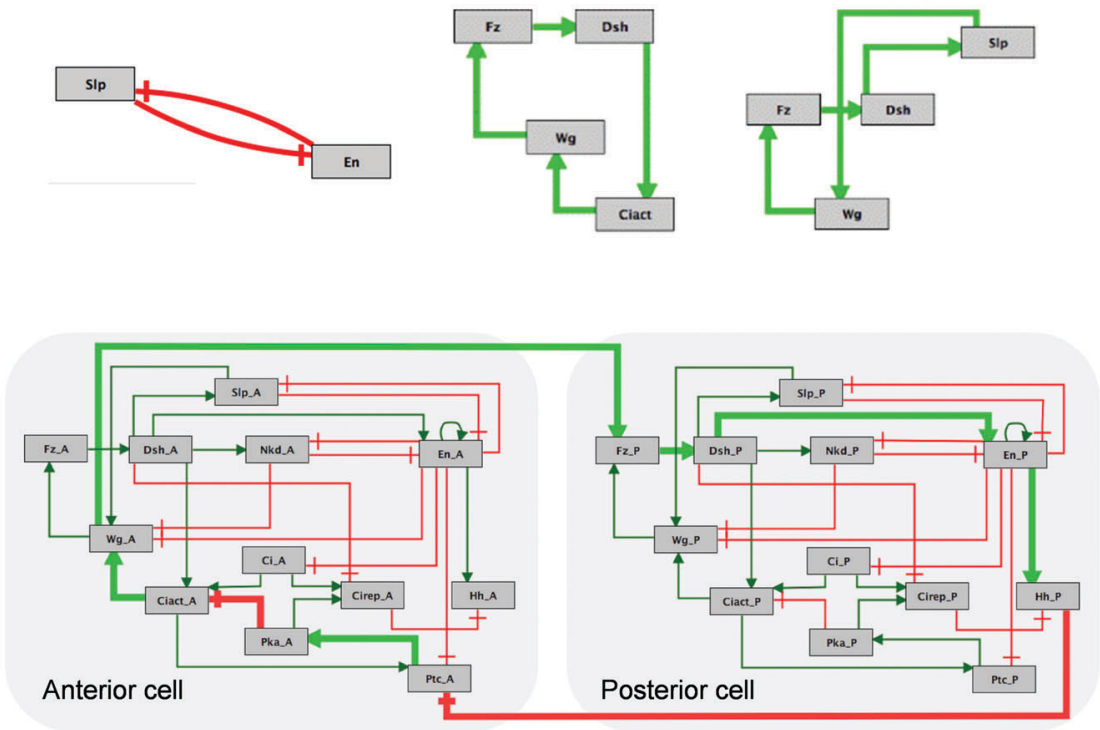

Fig. 3. Functional feedback circuits. The functional intra-cellular circuits are shown at the top, while the unique functional inter-cellular circuit is depicted in the bottom panel (highlighted with thicker lines).

finding that $\mathrm{Hh}$ signal is dispensable in the absence of Ptc, indicating that the role of $\mathrm{Hh}$ is to inhibit Ptc, in order to allow the activation of the Hh-pathway (cf. Introduction).

Double loss-of-function wg; ptc mutants have a unique stable state lacking both $w g$ and en expressions. The lack of $\mathrm{Wg}$ impedes the activation of Dsh in the En-cell, further leading to the loss of en expression, in agreement with experimental results (Hooper, 1994; DiNardo et al., 1988). However, for a loss-offunction ptcmutation combined with a partial loss-of-function $w g$ mutation, wg expression remains possible at a low level in some cells, while en expression is completely lost, in agreement with published results (Hooper, 1994). Indeed, as $w g$ is expressed at its medium level (i.e., $\mathrm{Wg}=1$ ), the autocrine but not the paracrine$W g$ pathway is functioning. Consequently, the expression of $e n$ is lost.

On the basis of our logical segment-polaritymodel, we can also easily simulate selected ectopic gene expressions. For example, when $e n$ is ectopically expressed, a unique stable state is obtained, lacking $w g$ expression, in agreement with experimental results (Heemskerk et al., 1991; Bejsovec and Wieschaus, 1993; Yoffe et al., 1995). This naturally results from the repression of $w g$ by En (Heemskerk et al., 1991; Alexandre and Vincent, 2003).

When $w g$ is ectopically expressed, the system has up to 41 non-symmetrical stable states. High Wg activity activates Dsh in all cells and thus enables the functionality of the positive SIp-En circuit. As a consequence, we obtain different patterns combining cells expressing En and cells expressing SIp (together with high levels of $\mathrm{Nkd}, \mathrm{Ci}$ and $\mathrm{Ci}[\mathrm{act}])$. Using the same priority classes as above, the system primarily reaches states characterised by a posterior expansion of En stripe, conserving the wild-type anterior border, as observed experimentally (Sampedro et al., 1993; Noordermeer et al., 1994; Noordermeer et al., 1995). Thus, in these embryos, two cell types can be distinguished: cells expressing genes $w g$ and $s / p$ but not $e n$, on the one hand, and cells expressing genes $w g$ and enbut not $s / p$ on the other hand. (Notice that, here, En and $\mathrm{Wg}$ can be both expressed in the same cell because En cannot repress the $w g$ transgene).

Although the ectopic $w g$ expression does not normally induce en expression throughout the whole parasegment, it does so in embryos lacking $s / p$ function, thereby indicating that $s / p$ prevents the induction of En throughout the parasegment despite the ubiquitous $\mathrm{wg}$ expression (Noordermeer et al., 1995). Indeed, the simulation of embryos ectopically expressing $w g$ and deficient for $s / p$ leads to a unique cell type, with expression of both $w g$ and $e n$.

\section{Discussion}

In Drosophila melanogaster, segmentation originates from the action of maternal organisers upon the zygotic segmentation gene system. This hierarchical system is composed of three cross-regulatory modules (sub-systems): the gap, the pair-rule and the segment polarity modules. Whereas the interactions among the gap and among the pair-rule genes consist essentially in intracellular transcriptional regulations, the interactions among the segment polaritygenes occur at the intra- and inter-cellular levels. This manuscript proposes a consistent formal qualitative model of the role of the segment polarity cross-regulatory module in the segmentation process in Drosophila embryo. Specifically, it accounts for the consolidation of the en and $w g$ expression pattern, initially set under the control of the pair-rule module, through specific inter-cellular interactions and signal transduction pathways.

In the introduction, three other segment polarity model analyses have been mentioned (von Dassow et al., 2000; von Dassow and Odell, 2002; Albert and Othmer, 2003; Ingolia, 2004). Each of these analyses aims at integrating diverse genetic and molecular data and at delineating the most crucial components and constraints involved in the formation of correct segmental borders. All these models (including ours) assume that the dynamics of the segment polarity gene network is largely defined by its topology (i.e. the interactions between the genes, the sign of each of these interactions and their different weights), rather than by fine-tuning of kinetic parameters. To some extend, this idea was already present in the model proposed by Meinhardt and Gierer (1980), well before the identification of the segmentation genes and the molecular nature of their interactions.

The delineation of the definite topology of the segment-polarity network from the analysis of published experimental data is nevertheless far from trivial. Indeed, the different studies mentioned above significantly differ with respect to the regulatory interactions considered (cf. Introduction), and consequently lead to different conclusions.

On the basis of their ODE model analysis, von Dassow et al. (2000) concluded that the segment polarity system is robust and 
that only loose constraints on the initial conditions have to be met to obtain the wild-type biological pattern. This pattern can even be attained when the initial conditions do not include an initial pulse of En and Wg. Ingolia's model proposes that the robustness of the segment polarity network is due specifically to the positive feedback of gene products on their own expression, and in the crossinhibitory circuit between s/pand enwhich plays an important role in the establishment of the final expression pattern of en and $w g$. On the basis of their Boolean model analysis, Albert and Othmer (2003) found that the deletion of cidoes not affect the pattern of the genes en, wgand $h h$. To explain this result, Albert and Othmer proposed that $s / p$ maintains the activation of $w g$, which in turn maintains the expression of $e n$ and $h h$. However, it has been shown that $s / p$ cannot be continuously expressed in the absence of $w g$ function (Cadigan et al., 1994). Furthermore, the maintenance of $w g$ expression in the $\mathrm{Wg}$-cell requires the $\mathrm{Hh}$ input from the adjacent En-cell and the Hh-signalling pathway in the $\mathrm{Wg}$-cell, which passes necessarily through the formation of $\mathrm{Ci}$ [act] (Méthot and Basler, 2001). Albert and Othmer further concluded that $s / p$ plays a crucial role in the delineation of the segment polarity expression pattern, through its control on wg. Finally, they proposed that a proper expression of $w g$ and ptc suffices to initiate a proper wild-type segment polarity expression pattern.

The revised model for the segment polaritymodule presented here (regulatory graph of Fig. $1 \mathrm{~A}$, together with the logical parameter values of Table 2) has been iterated and properly interconnected through $\mathrm{Wg}$ and $\mathrm{Hh}$ signallings to model a row of six cells (or regions, as each of them might encompass more than just one cell), thus covering a whole segment of the embryo (Fig. 1B).

This model accounts for the mutual activation of $e n$ and $w g$ in two juxtaposed cells, flanking the forming segmental borders. Encell and Wg-cell are characterised by a particular combination of active segment polaritygenes (or gene products), corresponding to the autocrine and paracrine $\mathrm{Wg}$-signalling pathways (operative upon the Wg-cell and the En-cell, respectively) together with the $\mathrm{Hh}$-signalling pathway (operative in the Wg-cell). Acting upon the En-cell, the paracrine Wg-pathway induces the formation and secretion of $\mathrm{Hh}$, ultimately leading to the activation of the $\mathrm{Hh}$ signalling pathway in the adjacent $\mathrm{Wg}$-cell, thereby forming an inter-cellular positive circuit.

Although most segment polarityfactors could be considered as binary devices, we were led to distinguish two functional levels for Wg, Nkd, Ci[act], Pka, and Ptc.We further assumed that the autocrine $\mathrm{Wg}$-signalling pathway requires lower $\mathrm{Wg}$ levels than the paracrine pathway. This allowed us to uncover subtle behaviours such as the maintenance of $w g$, in the $\mathrm{Wg}$-cell, without eninduction in the adjacent cells, in loss-of function ptcand partial loss-of-function $w g$ mutants. Fully functional $\mathrm{Wg}$ (autocrine and paracrine) and Hh pathways are needed to reproduce all experimental observations (in particular the effect of' $w g$ partial lossfunction). More precisely, high levels of $w g$ expression require high levels of $\mathrm{Ci}[\mathrm{act}]$, which in turn require the combination of autocrine and paracrine Wg-signalling, together with $\mathrm{Hh}$-signalling pathways.

Our model analysis implies that the consolidation of enand $w g$ expression patterns requires the autocrine function of $\mathrm{wg}$, i.e., the direct action of the secreted $\mathrm{Wg}$ product upon the cell that secretes it. Could Hh, secreted from the En-cell, also perform an autocrine function? It has been reported that Hh can be internalised into posterior compartment cells (Callejo et al., 2006), in spite of the fact that these lack Ptc receptor because the gene en expressed in these cells represses ptcexpression (Ingham et al., 1991). How such a process takes place and whether such internalisation of $\mathrm{Hh}$ performs any biological function remain open questions. If it has a function, it must be implemented through a different Hh pathway because the cells expressing enand secreting $\mathrm{Hh}$ lack $\mathrm{Ci}$, the effector of the canonical pathway studied here (Dominguez etal., 1996; Méthot and Basler, 1999; Alexandre and Vincent, 2003; Eaton and Kornberg, 1990)

The analysis of the wild-type model behaviour suggests that the pair-rule pattern is instrumental not only in determining the activation of genes engrailed and wingless in rows of adjacent cells, but also for the consolidation of their expressions. This explains the observed temporal overlapping of pair-rule and segment polarity gene expressions. In this respect, according to our analysis, Slp and Nkd play a crucial role in the delineation of engrailed and wingless expression domains beyond their specification by pair-rules factors (such as Eve and Ftz), to enable the full activation of $\mathrm{Wg}$ and $\mathrm{Hh}$ signalling pathways. We further assumed that the highest level of $\mathrm{Ci}[\mathrm{act}]$ overcomes $w g$ repression by Nkd, thereby explaining why, in the wild-type, Nkd represses $w g$ only in cell 2 (and not in cell 3, where Nkd is also initially expressed) (Zeng et al., 2000). Furthermore, we considered that En, either directly or indirectly, represses $n k d$. Thus, we obtain similar cross-inhibitory relationships between en and $n k d$ and between en and $s / p$. Consequently, en can be expressed in the presence of Nkd, provided the absence of SIp. These assumptions have been introduced to account for the initial expression of $n k d$ in cell 4, where enis also expressed, ultimately leading to $n k d$ repression (Zeng et al., 2000). When we selected parameters allowing the diffusion of $\mathrm{Wg}$ towards the posterior cells, the model predicted a state corresponding to the expected pattern that has been observed in the loss-of-function $n k d$ mutants. This suggests a series of investigations designed to see if $\mathrm{Nkd}$ retards $\mathrm{Wg}$ diffusion.

Finally, our model analysis emphasises the dual role played by Protein kinase A through the phosphorylation of Cubitus interruptus, the effector molecule of the Hedgehog signalling pathway.

The consistency of our model with available experimental data has been evaluated through systematic simulations of loss-offunctions mutations or ectopic expressions of segment-polarity genes, which all led to results in qualitative agreement with published data. In particular, we could recover the peculiar behaviour of loss of function ptc mutants, with an anterior ectopic expression of enassociated with an anterior expansion of the $\mathrm{wg}$ expression domain. Similarly, we could successfully simulate the striking phenotype of loss-of-function $n k d$ mutants, where the posterior expansion of En-stripe induces $w g$ in the adjacent posterior cell. In this respect, as we had to allow an increased diffusion of $\mathrm{Wg}$ to reach this result, our analysis supports a possible role of $\mathrm{Nkd}$ in the restriction of $\mathrm{Wg}$ diffusion (Zeng et al., 2000; Moline et al., 1999).

\section{Prospects}

Primarily based on genetic data, the segment polarity model presented here aims at better understanding how the expression of $e n$ and $w g$ in juxtaposed cells, once activated by the pair-rule 
network, becomes consolidated through inter- and intra-cellular interactions between the segment polarity genes. This corresponds to the last step of segmentation in Drosophila embryos, i.e. the establishment of the (para)segmental boundaries, which occur at the juxtaposition of cells expressing enand cells expressing $w g$. Certainly, we have overlooked the roles of additional genes here, as we have focused on representative genes of the $\mathrm{Hh}$ - and Wg-signalling pathways, which implement the interactions between the En versus Wg expressing cells. Furthermore, some of the considered genes are also involved in other biological processes, such as, for example, the internal patterning and cell specification of the segments, once these became formed, or yet the growth and organisation of adult appendages, such as the wing and the leg. We believe that the core of our model can be used to study different differentiation involving the canonical $\mathrm{Hh}$ and $\mathrm{Wg}$-signalling pathways. Notwithstanding, we are aware that specific Hh- and/or Wg-target genes should be added to develop more realistic biological analyses of these processes.

The model presented here can also be applied to the development of the wing and leg discs, with the addition of another gene, decapentaplegic (dpp), whose function is under the control of the Hh signalling pathway. For example, the wing disc is composed of two distinct populations of cells, which form the anterior and the posterior compartments. Posterior compartment cells express continuously enand secrete $\mathrm{Hh}$, which induces dppexpression in the anterior compartment cells adjacent to the anterior-posterior (AP) compartment border. This activation involves the production of $\mathrm{Ci}$ [act]. However, in the anterior compartment cells away from the AP boundary, the default form of $\mathrm{Ci}, \mathrm{Ci}[\mathrm{rep}]$, represses $d p p$ (reviewed in Ingham, 1998; McMahon, 2000; Ingham and McMahon, 2001). Similarly to the situation of the formation of parasegment boundaries, simulation of loss-of-function and dominant-negative mutations in gene cican be simulated through the selection of appropriate values for the variables corresponding to Ci, Ci[act], Ci[rep] and Dpp.

\section{Materials and Methods}

\section{Logical modelling of genetic networks}

In the context of this qualitative approach, genetic regulatory interactions are represented in terms of a directed graph (Chaouiya et al., 2003). In a logical regulatory graph, each node (gene or regulatory product) is assigned a maximal/evel, which defines the highest qualitative functional level taken by the regulatory node (this maximal level equals 1 in the simplest, Boolean case). Whenever distinct functional concentrations of the same regulatory product need to be considered, multi-level variables are used. Each arc embodies a regulatory interaction and is assigned a threshold. This threshold defines the smallest functional level of the interaction source for which the interaction is operative. Logical parameters qualitatively describe the effects of each interaction or combination of interactions controlling the functional state of a given element of the network. Thus, for a node, there are as many parameters as the number of possible combinations of interactions acting on this node. Per default, these parameters are set to zero. Defining non zero parameters thus amounts to single out the combinations of interactions which enable the activation of the different regulatory components and the qualitative recovery of all documented wild type and mutant gene expression patterns.

A state of the network is represented by a vector, which encompasses the current (discrete) level of each node. Given a state, one can determine which interactions are operative on each gene. Using the values of the logical parameters, one can then identify the nodes called to change their levels. In general, for a given state, we consider all possible elementary transitions (i.e. switching of only one regulatory component, to a neighbouring integer level), thus leading to as many outgoing arrows as updating calls (asynchronous updating). Depending on the structure of the regulatory graph and on the values of the logical parameters, the network encompasses a large but finite number of dynamical pathways.

\section{Computational tools for the analysis of logical model properties}

The GINsim software supports the definition of logical regulatory graphs, from the network structure to the logical parameters, through a user-friendly interface (Gonzalez et al., 2006). It further allows the simulation and the analysis of logical models. A simulation is performed on the basis of selected initial state(s) and results in a state transition graph, which represents all possible trajectories from the specified initial conditions. GINsim further allows the identification of stable states, as well as the computation of a shortest path between two given states. GINsim can be freely downloaded from a dedicated web site, which also provides extensive documentation and a model repository (http://gin.univmrs.fr/GINsim).

When facing large regulatory networks (encompassing dozens of components), it becomes impossible to perform exhaustive simulations. As we are particularly interested in the delineation of differentiated expression states, usually represented by stable states, we have used the following strategy.

First, we have developed an efficient algorithm to determine all the stable states of a logical model, without simulating the system. Our approach leans on a compact computational structure (Ordered Multivalued Decision Diagrams) for the representation of the logical functions associated to the regulatory components (Naldi et al., 2007).

Next, it is necessary to verify which of the identified stable states can be actually reached from proper initial conditions. In the discrete modelling context, this problem has already been extensively addressed by computer scientists, leading to the development of various computational tools. Here, we have leaned on INA (for Integrated Net Analyzer), a software package supporting the analysis of discrete Petri nets (http:// www2.informatik.hu-berlin.de/ starke/ina.html). Petri nets constitute a convenient mathematical and graphical framework to represent discrete models with concurrency (for an introduction to Petri nets, see Murata, 1989). Logical models can easily be translated into standard Petri nets (Chaouiya et al., 2006), and a specific module has been added to GINsim (version in development) to automatically export logical models into INA storage format.

Given a Petri net and an initial state, INA builds the state transition graph and determines the stable states (terminal nodes). Unfortunately, for large regulatory systems, the size of the state transition graph can be huge and thus impossible to build entirely. However, in practice, it is sufficient to determine the closest stable states, or the stable states lying within some distance interval, which can be easily defined with INA. We have further used an option allowing a reduction of the state transition graph by ignoring the paths, which lead to the same states (stubborn reduction).

When asynchronous updating is used for really complex cases, the definition of simple transition priority classes becomes valuable (Fauré et al., 2006). Indeed, the consideration of priorities amounts to discard relatively slow transitions, which are associated with a lower priority. In the present case, two priority classes have been defined. The high priority class includes all transitions corresponding to protein modification events (receptor in/activation, proteolysis, de/phosphorylation). This class includes $\mathrm{Ci}[\mathrm{act}], \mathrm{Ci}[\mathrm{rep}], \mathrm{Fz}$, Dsh and Pka. The low priority class encompasses all de novogene expression processes. This class comprises $\mathrm{Ci}$, Wg, Nkd, En, Slp, Hh and Ptc.

The logical framework also provides original tools to delineate the dynamical roles of specific regulatory circuits embedded within complex regulatory networks (for an introduction to feedback circuits, and their 
roles see Thomas et al., 1995; Thieffry, 2007). In the discrete (graphtheoretic) framework, a regulatory circuit can be defined as a simple circular chain of oriented interactions. When interaction signs are fixed (positive for activations, negative for inhibitions), the sign of a circuit amounts to the product of the signs of its constitutive interactions. This leads to the definition of two classes of circuits, positive versus negative circuits, which can generate strikingly different biological and dynamical properties: multiple stable states (or, more generally, multiple attractors) and differentiation versushomeostasis and sustained oscillatory behaviour. However, the sole presence of a circuit in a regulatory graph does not suffice to ensure such properties. When a circuit does generate the associated behaviour, we say that it is functional. In the logical framework, the functionality of a circuit depends on the values of the logical parameters associated to each regulatory component involved in the circuit, and thus on the values of the external inputs controlling these elements. We have recently implemented a novel algorithm into GINsim to efficiently compute circuit functionality domains (in terms of the values of the input components) (Naldi et al., 2007). Applied to our model of the segment polarity network, this approach has led to the identification of a very limited number of specific intra- and inter-cellular circuits, each playing a crucial role in the dynamical behaviour of the system. These results have been further validated through the simulation of genetic perturbations specifically affecting each of these circuits.

The simulation of genetic perturbations is straightforward in the logical framework. A loss-of-function mutation at a given gene implies that this gene produces a non-functional product (or no product at all), which amounts to assign the value zero to the corresponding logical variable (regulatory product concentration) and parameters. In contrast, the ectopic expression of a gene implies that this gene is expressed in an unregulated manner beyond its normal spatial-temporal expression domain. This can be accomplished by forcing the corresponding element to take higher values (for a more detailed description of this formal treatment of mutations see Thieffry and Sánchez, 2002). In this respect, GINsim provides an intuitive interface to trap single or multiple components into selected intervals of discrete values, in combination with the specification of proper initial conditions.

\section{Acknowledgements}

We thank A. Naldi for his active participation in the development of GINsim. We are grateful to $S$. Gilbert for his comments on the manuscript. $C$. Chaouiya and D. Thieffry acknowledge financial support from the French Research Ministry through the ACI IMPbio and ANR BioSys programme. L. Sánchez is supported by grant BMC2002-02858 from C.I.C.Y.T., Ministerio de Educación y Ciencia. Collaboration between the two groups has been enhanced by a grant in the context of a CSIC-CNRS cooperation program.

\section{References}

ALBERT, R. and OTHMER, H.G. (2003). The topology of the regulatory interactions predicts the expression pattern of the segment polarity genes in Drosophila melanogaster. J. theor. Biol. 223: 1-18.

ALCEDO, J., AYZENZON, M., VONOHLEN, T., NOLL, M. and HOOPER, J.E. (1996). The Drosophila smoothenedgene encodes a seven-pass membrane protein, a putative receptor for the hedgehog signal. Ce//86: 221-232.

ALEXANDRE, C., JACINTO, A. and INGHAM, P.W. (1996). Transcriptional activation of hedgehog target genes in Drosophila is mediated directly by the cubitus interruptus protein, a member of the GLI family of zinc finger DNA-binding proteins. Gene Dev. 10: 2003-2013.

ALEXANDRE, C. and VINCENT, J.P. (2003). Requirements for transcriptional repression and activation by Engrailed in Drosophila embryos. Development 130: 729-739.

ALVES, G., LIMBOURG-BOUCHON, B., TRICOIRE, H., BRISSARD-ZAHRAOUI, J., LAMOUR-ISNARD, C. and BUSSON, D. (1998). Modulation of Hedgehog target gene expression by the Fused serine-threonine kinase in wing imaginal discs. Mech. Dev. 78: 17-31.

ALVES, F. and DILÃO, R. (2006). Modelling segmental patterning in Drosophila: Maternal and gap genes. J. Theor. Biol. 241: 342-359.

AXELROD, J.D., MILLER, J.R., SHULMAN, J.M., MOON, R.T. and PERRIMON, N (1998). Differential recruitment of Dishevelled provides signaling specificity in the planar cell polarity and Wingless signaling pathways. Genes Dev. 12: 2610 2622

AZA-BLANC, P., RAMIREZ-WEBER, F.A., LAGET, M.P., SCHWARTZ, C. and KORNBERG, T.B. (1997). Proteolysis that is inhibited by Hedgehog targets Cubitus interruptus protein to the nucleus and converts it to a repressor. $\mathrm{Ce} / / 89$ : 1043-1053.

BEJSOVEC, A. and MARTÍNEZ-ARIAS, A. (1991). Roles of wingless in patterning the larval epidermis of Drosophila. Development 113: 471-487.

BEJSOVEC, A. and WIESCHAUS, E. (1993). Segment polarity gene interactions modulate epidermal patterning in Drosophila embryos. Development 119: 501517.

BIENZ, M. and CLEVERS, H. (2003). Armadillo/beta-catenin signals in the nucleus - proof beyond a reasonable doubt? Nat. Cell Biol. 5: 179-182.

BODNAR, J.W. (1997). Programming the Drosophila embryo. J. Theor. Biol. 188: 391-445.

BOUTROS, M. and MLODZIK, M. (1999). Dishevelled: at the crossroads of divergent intra-cellular signaling pathways. Mech. Dev. 83: 27-37.

CALLEJO, A., TORROJA, C., QUIJADA, L. and GUERRERO, I, (2006). Hedgehog lipoid modifications are required for Hedgehog stabilization in the extracellular matrix. Development 133: 471-483.

CADIGAN, K.M., GROSSNIKLAUS, U. and GEHRING, W.J. (1994). Localized expression of Sloppy paired protein maintains the polarity of Drosophila parasegments. Genes Dev. 8: 899-913.

CAMPOS-ORTEGA, J. and HARTENSTEIN, V. (1985). The Embryonic Development of Drosophila melanogaster. Berlin: Springer.

CHAOUIYA, C., REMY, E., MOSSÉ, B. and THIEFFRY, D. (2003). Qualitative analysis of regulatory graphs: a computational tool based on a discrete formal framework. Lect. Notes Control Inf. Sci. 294: 119-126.

CHAOUIYA, C., REMY, E. and THIEFFRY, D. (2006). Qualitative Petri Net modelling of genetic networks. Lect. Notes Comput. Sci. 4220: 95-112.

CHEN, Y. and STRUH, G. (1996). Dual roles of Patched in sequestering and transducing Hedgehog. Cel/87: 553-563.

CHEN, C. and STRUHL, G. (1999). Wingless transduction by the Frizzled and Frizzled2 proteins of Drosophila. Development 126: 5441-5452.

CHEN, Y., CARDINAUX, J.R., GOODMAN, R.H., SMOLIK, S.M. (1999). Mutants of cubitus interruptus that are independent of PKA regulation are independent of Hedgehog signaling. Development 126: 3607-3616.

CLIFFE, A., HAMADA, F. and BIENZ, M. (2003). A role of dishevelled in relocating axin to the plasma membrane during wingless signaling. Curr. Biol. 13: 960-966.

DENEF, N., NEUBUSER, D., PÉREZ, L. and COHEN, S.M. (2000). Hedgehog induces opposite changes in turnover and subcellular localization of patched and smoothened. Cel/102: 521-531.

DINARDO, S., SHER, E., HEEMSKERK, J.J., KASSI, J.A., O'FARRELL, P.H. (1988). Two-tiered regulation of spatially patterened engrailedgene expression during Drosophila embryogenesis. Nature 332: 604-609.

DOMINGUEZ, M., BRUNNER, M., HAFEN, E. and BASLER, K. (1996). Sending and receiving the hedgehog signal: control by the Drosophila Gli protein Cubitus interruptus. Science 272: 1621-1625.

EATON, S. and KORNBERG, T.B. (1990). Repression of $c i-D$ in posterior compartments of Drosophila by engrailed. Genes Dev. 4: 1068-1077.

FAURÉ, A., NALDI, A., CHAOUIYA, C. and THIEFFRY, D. (2006). Dynamical analysis of a generic Boolean model for the control of the mammalian cell cycle. Bioinformatics 22: e124-31.

FORBES, A.J., NAKANO, Y., TAYLOR, A.M. and INGHAM, P.W. (1993). Genetic analysis of hedgehogsignalling in the Drosophila embryo. DevelopmentSuppl: 115-124.

GALLET, A., ANGELATS, C., KERRIDGE, S. and THÉROND, P.P. (2000). Cubitus interruptus-independent transduction of the Hedgehog signal in Drosophila. Development 127: 5509-5522. 
GONZALEZ, A.G., NALDI, A., SÁNCHEZ, L., THIEFFRY, D. and CHAOUIYA, C. (2006). GINsim: a software suite for the qualitative modelling, simulation and analysis of regulatory networks. BioSystems 84: 91-100.

HEEMSKERK, J., DINARDO, S., KOSTRIKEN, R. and O'FARRELL, P.H. (1991). Multiple modes of engrailed regulation in the progression towards cell fate determination. Nature 352: 404-410.

HEPKER, J., WANG, Q.T., MOTZNY, C.K., HOLMGREN, R.A. and ORENIC, T.V. (1997). Drosophila cubitus interruptus forms a negative feedback loop with patched and regulates expression of Hedgehog target genes. Development 124: 549-558.

HIDALGO, A. (1991). Interactions between segment polarity genes and the generation of the segmental pattern in Drosophila. Mech. Dev. 35: 77-87.

HOOPER, J. (1994). Distinct pathways for autocrine and paracrine Wingless signalling in Drosophila embryos. Nature 372: 461-464.

HOUCHMANDZADEH, B., WIESCHAUS, E. and LEIBLER, S. (2002). Establishment of developmental precision and proportions in the early Drosophila embryo. Nature 415: 798-802.

INGHAM, P.W. (1998). Transducing Hedgehoh: the story so far. EMBO J. 17: 35053511.

INGHAM, P.W. (1991). Segment polarity genes and cell patterning within the Drosophila body segment. Curr. Opin. Genet. Dev. 1: 261-267.

INGHAM, P.W., TAYLOR, A.M. and NAKANO, Y. (1991). Role of the Drosophila patchedgene in positional signalling. Nature 353: 184-187.

INGHAM, P.W. and MARTÍNEZ-ARIAS, A. (1992). Boundaries and fields in early embryos. Cel/68: 221-235.

INGHAM, P.W. and HIDALGO, A. (1993). Regulation of winglesstranscription in the Drosophila embryo. Development 117: 283-291.

INGHAM, P.W. and McMAHON, A.P. (2001). Hedgehog signaling in animal development: paradigms and principles. Genes Dev. 15: 3059-3087.

INGOLIA, N.T. (2004). Topology and robustness in the Drosophilasegment polarity network. PLOS Biol. 2: 805-815.

JAEGER, J., BLAGOV, M., KOSMAN, D., KOZLOV, K., MANU, N., MYASNIKOVA, E., SURKOVA, S., VANARIO-ALONSO, C.E., SAMSONOVA, M., SHAR, D.H. and REINITZ, J. (2004a). Dynamical analysis of regulatory interactions in the gap gene system of Drosophila melanogaster. Genetics 167: 1721-1737.

JAEGER, J., SURKOVA, S., BLAGOV, M., JANSSENS, H., KOSMAN, D., KOZLOV, K., MANU, N., MYASNIKOVA, E., VANARIO-ALONSO, C.E., SAMSONOVA, M., SHARP, D.H. and REINITZ, J. (2004b). Dynamic control of positional information in the early Drosophila embryo. Nature 430: 368-371.

JIA, J.H., AMANAL, K., WANG, G.L., TANG, J., WANG, B. and JIANG. J. (2002). Shaggy/GSK3 antagonizes Hedgehog signalling by regulating Cubitus interruptus. Nature 416: 548-552.

JIANG, J. and STRUHL, G. (1995). Protein kinase A and Hedgehog signalling in Drosophila limb development. Cel/ 80: 563-572.

JIANG, J. (2002). Degrading Ci: who is Cul-pable? Genes Dev. 16: 2315-2321.

JÜRGENS, G., WIESCHAUS, E., NÜSSLEIN-VOLHARD, C. and KLUDING, H. (1984). Mutations affecting the pattern of the larval cuticle in Drosophila melanogaster. II. Zygotic loci on the third chromosome. Wilhelm Roux's Arch. Dev. Biol. 193: 283-295.

KALDERON, D. (2002). Similarities between the Hedgehog and Wnt signaling pathways. Trends Cell. Biol. 12: 523-531.

KOBAYASHI, M., FUJIOKA, M., TOLKUNOVA, E.N., DEKA, D., ABU-SHAAR, M., MANN, R.S. and JAYNES, J.B. (2003). Engrailed cooperates with extradenticle and homothorax to repress target genes in Drosophila. Development 130: 741751.

LEE, J.L. von KESSLER, D.P., PARKS, S. and BEACH, P.A. (1992). Secretion and localized transcription suggest a role in positioning signaling for products of the segmentation gene hedgehog. Cel/71: 33-50.

LEPAGE, T., COHEN, S., DÍAZ-BENJUMEA, F.J. and PARKHURST, S.M. (1995) Signal transduction by cAMP-dependent protein kinase A in Drosophila limb patterning. Nature 373: 711-715.

LI, L.H., YUAN, H., WEAVER, C.D., MAO, J., FARR III, G.H., SUSSMAN, D.J., LONKERS, J., KIMELMAN, D. and WU, D. (1999). Axin and Frat1 interact with Dvl and GSK, bridging Dvl to GSK in Wnt-mediated regulation of LEF-1. EMBO J. 18: 4233-4240
MARTIN, V., CARRILLO, G., TORROJA, C. and GUERRERO, I. (2001). The sterolsensing domain of Patched protein seems to control Smoothened activity through Patched vesicular trafficking. Curr. Biol. 11: 601-607.

MARTÍNEZ-ARIAS, A. and LAWRENCE, P. (1985). Parasegments and compartments in the Drosophila embryo. Nature 313: 639-642.

MARTÍNEZ-ARIAS, A., BAKER, N.E. and INGHA, P.W. (1988). Role of segment polarity genes in the definition and maintenance of cell states in the Drosophila embryo. Development 103: 325-338.

McMAHON, A.P. (2000). More surprises in the Hedgehog signaling pathway. Cell 100: $185-188$.

MEINHARDT, H. and GIERER, A. (1980). Generation and regeneration of sequences of structures during morphogensis. J. Theor. Biol. 85: 429-450.

MEINHARDT, H. (1982). Models of Biological pattern formation. Academic Press, London.

MEINHARDT, H. (1986). Hierarchical inductions of cell states: a model for segmentation in Drosophila. J. Cell Sci. Suppl. 4: 357-381.

MÉTHOT, N. and BASLER, K. (1999). Hedgehog controls limb development by regulating the activities of distinct transcriptional activator and repressor forms of Cubitus interruptus. Cel/96: 819-831.

MÉTHOT, N. and BASLER, K. (2000). Suppressor of fused opposes hedgehog signal transduction by impeding nuclear accumulation of the activator form of Cubitus interruptus. Development 127: 4001-4010.

MÉTHOT, N. and BASLER, K. (2001). An absolute requirement for Cubitus interruptus in Hedgehog signaling. Development 128: 733-742.

MOLINE, M.M., SOUTHERN, C. and BEJSOVEC, A. (1999). Directionality of Wingless protein transport influences epidermal patterning in the Drosophila embryo. Development 126: 4375-4384.

MOTZNY, C. and HOLMGREN, R.A. (1995). The Drosophila Cubitus interruptus protein and its role in the wingless and hedgehog signal transduction pathways. Mech. Dev. 52: 137-150.

MULLEN, J.R. and DINARDO, S. (1995). Establishing parasegments in Drosophila embryos: roles of the odd-skipped and naked genes. Dev. Biol. 169: 295-308.

MULLER, B. and BASLER, K. (2000). The repressor and activator forms of Cubitus interruptus control Hedgehog target genes through common generic Gli-binding sites. Development 127: 2999-3007.

MURATA, T. (1989). Petri Nets: Properties, Analysis and Applications. Proc IEEE 77: $541-580$.

NALDI, A., THIEFFRY, D. and CHAOUIYA, C. (2007). Decision Diagrams for the Representation and Analysis of Logical Models of Genetic Networks. Lect. Notes Comput. Sci. 4695: 233-247.

NOORDERMEER, J., KLINGENSMITH, J., PERRIMON, N. and NUSSE, R. (1994). Dishevelledand armadillo act in the Wingless signaling pathway in Drosophila. Nature 367: 80-83.

NOORDERMEER, J., KLINGENSMITH, J. and NUSSE, R. (1995). Differential requirements for segment polarity genes in wingless signaling. Mech. Dev. 51: 145-155.

NYBAKKEN, K.E., TURCK, C.W., ROBBINS, D.J. and BISHOP, J.M. (2002). Hedgehog-stimulated phosphorylation of the kinesin-related protein Costal2 is mediated by the serine/threonine kinase fused. J. Biol. Chem. 277: 2463824647.

NYBAKKEN, K.E. and PERRIMON, N. (2002). Hedgehog signal transduction: recent findings. Curr. Opin. Genet. Dev. 12: 503-511.

OHLMEYER, J.T. and KALDERON, D. (1998). Hedgehog stimulates maturation of Cubitus interruptus into a labile transcriptional activator. Nature 396: 749-753.

PAI, L.M., ORSULIC, S., BEJSOVEC, A. and PEIFER, M. (1997). Negative regulation of Armadillo, a Wingless effector in Drosophila. Development 124: 2255-2266.

PAN, D. and RUBIN, G. (1995). CAMP-dependent protein kinase and hedgehog act antagonistically in regulating decapentaplegictranscription in Drosophilaimaginal discs. Cel/80: 543-552.

PANKRATZ, M.J. and JÄCKLE, H. (1993). Blastoderm segmentation. In The Development of Drosophila melanogaster, ed. Bates, M. and Martínez-Arias, A., pp. 467-516. Cold Spring Harbor Laboratory, New York.

PRÉAT, T. (1992). Characterization of Suppressor of fused, a complete suppressor 
of the fused segment polarity gene of Drosophila melanogaster. Genetics 132: 725-736.

PRÉAT, T., THÉROND, P.P., LIMBOURG-BOUCHON, B., PHAM, A., TRICOIRE, H., BUSSON, D. and LAMOUR-ISNARD, C. (1993). Segmental polarity in Drosophila melanogaster. genetic dissection of fused in a Suppressor of fused background reveals interaction with costal-2. Genetics 135: 1047-1062.

PRICE, M.A. and KALDERON, D. (1999). Proteolysis of cubitus interruptus in Drosophila requires phosphorylation by protein kinase A. Development 126: 4331-4339.

PRICE, M.A. and KALDERON, D. (2002). Proteolysis of the Hedgehog signaling effector Cubitus interruptus requires phosphorylation by glycogen synthase kinase 3 and casein kinase 1. Cel/108: 823-835.

REINITZ, J., KOSMAN, D., VANARIO-ALONSO, C.E. and SHARP, D.H. (1998). Stripe forming architecture of the gap gene system. Dev. Genet. 23: 11-27.

RIVERA-POMAR, R. and JÄCKLE, H. (1996). From gradients to stripes in Drosophila embryogenesis: filling in the gaps. Trends Genet. 12: 478-483.

ROBBINS, D., NYBAKKEN, K., KOBAYASHI, R., SISSON, J.C., BISHOP, J.M. and THÉROND, P.P. (1997). Hedgehog elicits signal transduction by means of a large complex containing the kinesis-related protein costal2. Cel/90: 225-234.

ROTHBACHER, U., LAURENT, M.N., DEARDORFF, M.A., KLEIN, P.S., CHO, K.W.Y. and FRASER, S.E. (2000). Dishevelled phosphorylation, subcellular localization and multimerization regulate its role in early embryogenesis. $E M B O$ J. 19: 1010-1022.

SALIC, A., LEE, E., MAYER, L. and KIRSCHNER, M.W. (2000). Control of betacatenin stability: reconstitution of the cytoplasmic steps of the Wnt pathway in Xenopus egg extracts. Mol. Cel/5: 523-532.

SAMPEDRO, J., JOHNSTON, P. and LAWRENCE, P.A. (1993). A role for wingless in the segmental gradient of Drosophila? Development 117: 677-687.

SÁNCHEZ, L. and THIEFFRY, D. (2001). A logical analysis of the Drosophila gapgene system. J. Theor. Biol. 211: 115-141.

SÁNCHEZ, L. and THIEFFRY, D. (2003). Segmenting the fly embryo: a logical analysis of the pair-rule cross-regulatory module. J. Theor. Biol. 224: 517-537.

SANSON, B., ALEXANDRE, C., FASCETTI, N. and VINCENT, J.P. (1999). Engrailed and hedgehog make the range of Wingless asymmetric in Drosophila embryos. Cel/98: 207-216.

SISSON, J.C., HO, K.S., SUYAMA, K. and SCOTT, M.P. (1997). Costal2, a novel kinesin-realted protein in the Hedgehog signaling pathway. Cel/90: 235-245.

SLUSARSKI, D.C., MOTZNY, C.K. and HOLMGREN, R.A. (1995). Mutations that alter the timing and pattern of cubitus interruptusgene expression in Drosophila melanogaster. Genetics 139: 229-240.

SPRENGER, F. and NÜSSLEIN-VOLHARD, C. (1993). The terminal system of axis determination in the Drosophila embryo. In The Development of Drosophila melanogaster, ed. Bates, M. and Martínez-Arias, A., pp. 365-386. Cold Spring Harbor Laboratory, New York.

STRUTT, H., THOMAS, C., NAKANO, Y., STARK, D., NEAVE, B., TAYLOR, A.M. and INGHAM, P.W. (2001). Mutations in the sterol-sensing domain of Patched suggest a role for vesicular trafficking in Smoothened regulation. Curr. Biol. 11: 608-613.

TABATA, T., EATON, S.E. and KORNBERG, T.B. (1992). The Drosophila hedgehoggene is expressed specifically in posterior compartment cells and is a target of engrailed function. Genes Dev. 6: 2635-2645.

TABATA, T., SCHWARTZ, C., GUSTAVSON, E., ALI, Z. and KORNBERG, T.B. (1995). Creating a Drosophila wing de novo, the role of engrailed, and the compartment border hypothesis. Development 121: 3359-3369.

THÉROND, P.P., BUSSON, D., GUILLEMET, E., LIMBOURG-BOUCHON, B., PRÉAT, T., TERRACOL, R., TRICOIRE, H. and LAMOUR-ISNARD, C. (1993). Molecular organisation and expression pattern of the segment polarity gene fused of Drosophila melanogaster. Mech. Dev. 44: 65-80.
THÉROND, P.P., ALVES, G., LIMBOURG-BOUCHON, B., TRICOIRE, H., GUILLEMET, E., BRISSARD-ZAHRAOUI, J., LAMOUR-ISNARD, C. and BUSSON, D. (1996). Functional domains of fused, a serine threonine kinase required for signaling in Drosophila. Genetics 142: 1181-1198.

THÉROND, P.P., BOUCHON, B.L., GALLET, A., DUSSILOL, F., PIETRI, T., van den HEUVEL, M. and TRICOIRE, H, (1999). Differential requirements of the Fused kinase for Hedgehog signalling in the Drosophila embryo. Development 126: 4039-4051.

THOMAS, R. (1991). Regulatory networks seen as asynchronous automata: a logical description. J. Theor. Biol. 153: 1-23.

THOMAS, R., THIEFFRY, D. and KAUFMAN, M. (1995). Dynamical behaviour of biological regulatory networks. I. Biological role of feedback loops and practical use of the concept of the loop-characteristic state. Bull. Math. Biol. 57: 247-276.

THIEFFRY, D. and SÁNCHEZ, L. (2002). Alternative epigenetic states understood in terms of specific regulatory structures. Ann. N.Y. Acad. Sci. 981: 135-153.

THIEFFRY, D. and SÁNCHEZ, L. (2004). Qualitative analysis of gene networks: Towards the delineation of trans-regulatory modules. In Modularity in Development and Evolution, ed. Schlosser, G. and Wagner, G., pp. 222-243. University of Chicago Press, Chicago, USA.

THIEFFRY, D. (2007). Dynamical roles of biological regulatory circuits. Brief Bioinfo. 8: 220-225.

van den HEUVEL, M., KLINGENSMITH, J., PERRIMON, N. and NUSSE, R, (1993). Cell patterning in the Drosophila segment: engrailed and wingless antigen distributions in segment polarity mutantss. Development Suppl: 105-114.

van den HEUVEL, M. and INGHAM, P.W. (1996). Comment - 'Smoothening' the path for hedgehogs. Trends Cell. Biol. 6: 451-453.

von DASSOW, G., MEIR, E., MUNRO, E.M. and ODELL, G.M. (2000). The segment polarity network is a robust development module. Nature 406: 188-192.

von DASSOW, G.and ODELL, G.M. (2002). Design and constraints of the Drosophila segment polarity module: Robust spatial patterning emerges from intertwined cell state switches. J. Exp. Zool. 294: 179-215.

WANG, G., WANG, B. and JIANG, J. (1999). Protein kinase A antagonizes Hedgehog signaling by regulating both the activator and repressor forms of Cubitus interruptus. Genes Dev. 13: 2828-2837.

WANG, Q.T. and HOLMGREN, R.A. (1999). The subcellular localization and activity of Drosophila Cubitus interruptus are regulated at multiple levels. Development 126: 5097-5106.

WANG, Q.T. and HOLMGREN, R.A. (2000). Nuclear import of Cubitus interruptus is regulated by Hedgehog via a mechanism distinct from $\mathrm{Ci}$ stabilization and $\mathrm{Ci}$ activation. Development 127: 3131-3139.

WANG, G.L., AMANAI, K., WANG, B. and JIANG, J. (2000). Interactions with Costal2 and Suppressor of fused regulate nuclear translocation and activity of Cubitus interruptus. Genes Dev. 14: 2893-2905.

WODARZ, A. and NUSSE, R. (1998). Mechanisms of Wnt signaling in development. Ann. Rev. Cell Dev. Biol. 14: 59-88.

YANAGAWA, S., van LEEWEN, F., WODARZ, A., KLINGENSMITHH, J. and NUSSE, R, (1995). The dishevelled protein is modified by wingless signaling in Drosophila. Genes Dev. 9: 1087-1097.

YOFFE, K., MANOUKIAN, A., WILDER, E.L., BRAND, A.H. and PERRIMON, N, (1995). Evidence for engrailed-independent wingless autoregulation in Drosophila. Dev. Biol. 170: 636-650

YOST, C., TORRES, M., MILLER, J.R., HUANG, E., KIMELMAN, D. and MOON, R.T. (1996). The axis-inducing activity, stability and subcellular distribution of beta-catenin is regulated in Xenopus embryos by glycogen synthase kinase 3. Genes Dev. 10: 1443-1454.

ZENG, W., WHARTON, K.A.Jr., MACK, J.A., WANG, K., GADBAU, M., SUYAMA, K., KLEIN, P.S. and SCOTT, M.P. (2000). Naked cuticle encodes an inducible antagonist of Wnt signalling. Nature 403: 789-795. 


\section{Appendix}

\section{Simulations and stable state analyses}

Considering the different situations (wild-type, and genetic perturbations), we have answered two questions. First, what are the potential stable states, independently of any initial condition? Second, given an initial state (compatible with the wild-type initial state shown in Fig. 2), what are the reachable stable states?

\section{Wild-type stable states for the isolated cell submitted to input $\mathrm{Hh}$ and $\mathrm{Wg}$ signals}

A preliminary analysis of the model amounts to consider a single isolated cell submitted to two input signals (Wg and $\mathrm{Hh}$ ).

In the case of the wild-type situation, Table A.1 lists all possible stable states depending on external inputs.

\section{Wild-type analysis}

We consider the complete model of 6 connected cells (Fig. 1). Note that with the 5 possible stable states of the above table for the isolated cells, there are 15625 possible combinations $\left(5^{6}\right)$ for the 6 cells interconnected, that is 15625 potential stable states. The complete State Transition Graph (STG), without specifying any initial condition, contains a huge number of states: $\left(3^{5} \cdot 2^{7}\right)^{6}>$ $10^{26}$ (this is the number of all possible states of the system).

But the inter-cellular interactions severely restrict the number of possible stable states, as there are exactly 65 stable states (among which 29 are symmetrical, egTTTCEW and WECTTT are symmetrical). Hence the model gives rise to 36 different patterns, in the wild type case.

It was not possible to construct the whole STG. But, we have verified that the two following states are reachable, the wild type state ( $1^{\text {rst }}$ one below) and the trivial state.

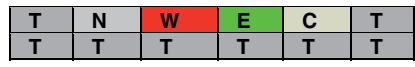

\section{Single loss-of-function wg, en, hh and ci mutants}

From initial conditions similar to those taken in the wild type case, but compatible with the considered loss-of-function, we have obtained the following unique stable state in the four situations:

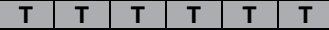

In the four cases, this state is unique and reachable. In the case of the loss-of-function cimutant, the stable state is rather similar to the trivial state, with $\mathrm{Ci}=0$.

\section{Loss-of-function ptc mutant}

There are exactly 64 stable states (among which 28 are symmetrical). Hence the model gives rise to 36 different patterns. The reachability analysis showed a number of reachable stable states, but using the two priority classes (as described in the text), we were able to prove that only the two following states are reachable.

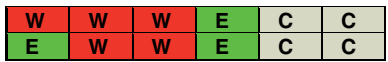

\section{Loss-of-function nkd mutant}

In this mutant situation, there are exactly 196 stable states (72 are symmetrical), hence 124 possible patterns. We reproduce in the table hereafter the 5 cellular states (a new one appears with a medium level of $\mathrm{Wg}$, it has been called $\mathrm{A})$ :

\begin{tabular}{ccccccccccccl} 
Wg & Fz & Dsh & Slp & Nkd & En & Hh & Ci & Ciact & Cirep & Pka & Ptc & \\
\hline 0 & 0 & 0 & 0 & 1 & 0 & 0 & 1 & 0 & 1 & 2 & 1 & T (trivial) \\
0 & 0 & 0 & 0 & 1 & 0 & 0 & 1 & 1 & 0 & 0 & 0 & C (CiCiact) \\
2 & 1 & 1 & 1 & 2 & 0 & 0 & 1 & 2 & 0 & 0 & 0 & W (Wg) \\
0 & 1 & 1 & 0 & 0 & 1 & 1 & 0 & 0 & 0 & 0 & 0 & E (En) \\
1 & 1 & 1 & 1 & 0 & 0 & 0 & 1 & 1 & 0 & 2 & 2 & A (Ciact) \\
\hline
\end{tabular}

We have not been able to observe the reachability of the expected stable state, generating a large STG, limiting the depth of the exploration, or yet considering priority classes. The stable states reached were not compatible with the experimental observations.

Consequently, we have modified the wiring, allowing $\mathrm{Wg}$ to

TABLE A1

\section{STABLE STATES FOR AN ISOLATED CELL SUBMITTED TO FIXED WG AND HH INPUTS}

\begin{tabular}{|c|c|c|c|c|c|c|c|c|c|c|c|c|c|c|}
\hline \multicolumn{2}{|c|}{ External inputs } & \multirow[b]{2}{*}{ Wg } & \multirow[b]{2}{*}{$\mathrm{Fz}$} & \multirow[b]{2}{*}{ Dsh } & \multirow[b]{2}{*}{ SIp } & \multirow[b]{2}{*}{ Nkd } & \multirow[b]{2}{*}{ En } & \multirow[b]{2}{*}{$\mathrm{Hh}$} & \multirow[b]{2}{*}{$\mathrm{Ci}$} & \multirow[b]{2}{*}{ Ciact } & \multirow[b]{2}{*}{ Cirep } & \multirow[b]{2}{*}{ Pka } & \multirow[b]{2}{*}{ Ptc } & \multirow[b]{2}{*}{ Letter code } \\
\hline $\mathrm{Wg}$ & $\mathrm{Hh}$ & & & & & & & & & & & & & \\
\hline 0 & 0 & 0 & 0 & 0 & 0 & 1 & 0 & 0 & 1 & 0 & 1 & 2 & 1 & $\mathbf{T}$ (trivial) \\
\hline 0 & 1 & 0 & 0 & 0 & 0 & 1 & 0 & 0 & 1 & 1 & 0 & 0 & 0 & C (CiCiact) \\
\hline 0 & 1 & 2 & 1 & 1 & 1 & 2 & 0 & 0 & 1 & 2 & 0 & 0 & 0 & w (Wg) \\
\hline 1 & 0 & 0 & 1 & 1 & 0 & 0 & 1 & 1 & 0 & 0 & 0 & 0 & 0 & $E(E n)$ \\
\hline 1 & 0 & 0 & 1 & 1 & 1 & 2 & 0 & 0 & 1 & 1 & 0 & 2 & 2 & $\mathbf{N}(\mathrm{Nkd})$ \\
\hline 1 & 1 & 2 & 1 & 1 & 1 & 2 & 0 & 0 & 1 & 2 & 0 & 0 & 0 & w \\
\hline 1 & 1 & 0 & 1 & 1 & 0 & 0 & 1 & 1 & 0 & 0 & 0 & 0 & 0 & E \\
\hline
\end{tabular}

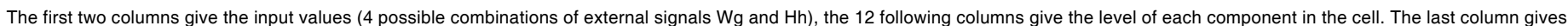
the name of the cellular state, together with a letter code. Finally, a color has been associated to each cellular state. 
diffuse towards more posterior cells. This new wiring leads to a slight restriction of the number of possible stable states (132 rather than 196 previously). Then, we were able to verify the presence in the reachability graph of the following expected stable pattern:

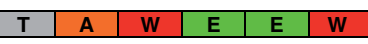

\section{Double loss-of-function ptc, hh mutant}

There are exactly 64 stable states (among which 28 are symmetrical). Hence the model gives rise to 36 different patterns which are the same as for the single loss-of-function ptc mutant (but the En cell lacks Hh). Moreover, we got the same reachability result, with the same 2 stable patterns.

\section{Double loss-of-function ptc, wg mutant}

We found a unique stable state, which is reachable from initial conditions similar to those of the wild type situations (with Ptc and Wg to zero):

\section{\begin{tabular}{|l|l|l|l|l|l|}
\hline $\mathbf{C}$ & $\mathbf{C}$ & $\mathbf{C}$ & $\mathbf{C}$ & $\mathbf{C}$ & $\mathbf{C}$ \\
\hline
\end{tabular}}

Loss-of-function ptc and partial loss-of-function wg mutant

There are exactly 64 stable states (among which 28 are symmetrical). Hence the model gives rise to 36 different patterns. A partial construction of the STG showed the reachability of the following patterns (the $\mathrm{Wg}$ cells have a medium level of $\mathrm{Wg}$ ):

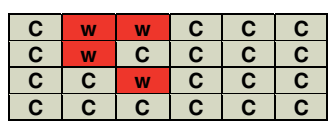

\section{Ectopic en expression}

One single stable pattern with the six cells in the same state where only En and Hh are expressed. This state is reachable from initial conditions similar to those of the wild type situation (with $\mathrm{En}=1$ for all cells).

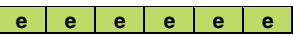

\section{Ectopic wg expression}

There are exactly 64 stable states (among which 28 are symmetrical). Hence the model gives rise to 36 different patterns. The simulation, using the 2 priority classes and considering the same initial condition as for the wild type case (but with $\mathrm{Wg}=2$ for all cells), the partial STG shows the following 4 reachable stable patterns (note that En and Nkd cells have an ectopic expression of $\mathrm{Wg})$ :

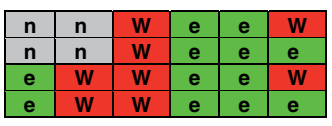

\section{Ectopic wg expression and loss-of-function slp mutant}

There exists a unique stable state, which is reached from the initial conditions:

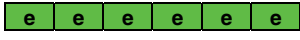

\section{Ectopic nkd expression}

There are 65 stable patterns (29 are symmetrical), hence 36 patterns are possible.

Among these, the trivial stable state is shown to be reachable (partial construction of the STG, limitation of the depth to 50, meaning that the trivial state is closer from the initial state than other possible pattern): 


\section{Further Related Reading, published previously in the Int. J. Dev. Biol.}

See our recent Special Issue Developmental Morphodynamics edited by Lev Beloussov and Richard Gordon at:

http://www.ijdb.ehu.es/web/contents.php?vol=50\&issue=2-3

See our recent Special Issue Ear Development edited by Fernando Giraldez and Bernd Fritzsch at: http://www.ijdb.ehu.es/web/contents.php?vol=51\&issue=6-7

Vertebrate somitogenesis: a novel paradigm for animal segmentation? Olivier Pourquié

Int. J. Dev. Biol. (2003) 47: 597-603

Segmentation: mono- or polyphyletic?

Elaine C Seaver

Int. J. Dev. Biol. (2003) 47: 583-595

Cell lineage analysis of pattern formation in the Tubifex embryo. II. Segmentation in the ectoderm.

A Nakamoto, A Arai and T Shimizu

Int. J. Dev. Biol. (2000) 44: 797-805

Induction of segmentation in polyps of Aurelia aurita (Scyphozoa,

Cnidaria) into medusae and formation of mirror-image medusa anlagen.

M Kroiher, B Siefker and S Berking

Int. J. Dev. Biol. (2000) 44: 485-490

Syntagms in development and evolution.

F Huang

Int. J. Dev. Biol. (1998) 42: 487-494

Laws for the dynamics of regulatory networks.

$\mathrm{R}$ Thomas

Int J Dev Biol. (1998) 42: 479-485

Segmentation and specification in the branchial region of the head: the role of the Hox selector genes.

F M Rijli, A Gavalas and P Chambon

Int. J. Dev. Biol. (1998) 42: 393-401

Segmentation of the vertebrate hindbrain: a time-lapse analysis.

$P$ M Kulesa and S E Fraser

Int. J. Dev. Biol. (1998) 42: 385-392

Proximo-distal development in the legs of Drosophila.

J P Couso and S A Bishop

Int. J. Dev. Biol. (1998) 42: 345-352
2006 ISI **Impact Factor $=3.577^{* *}$
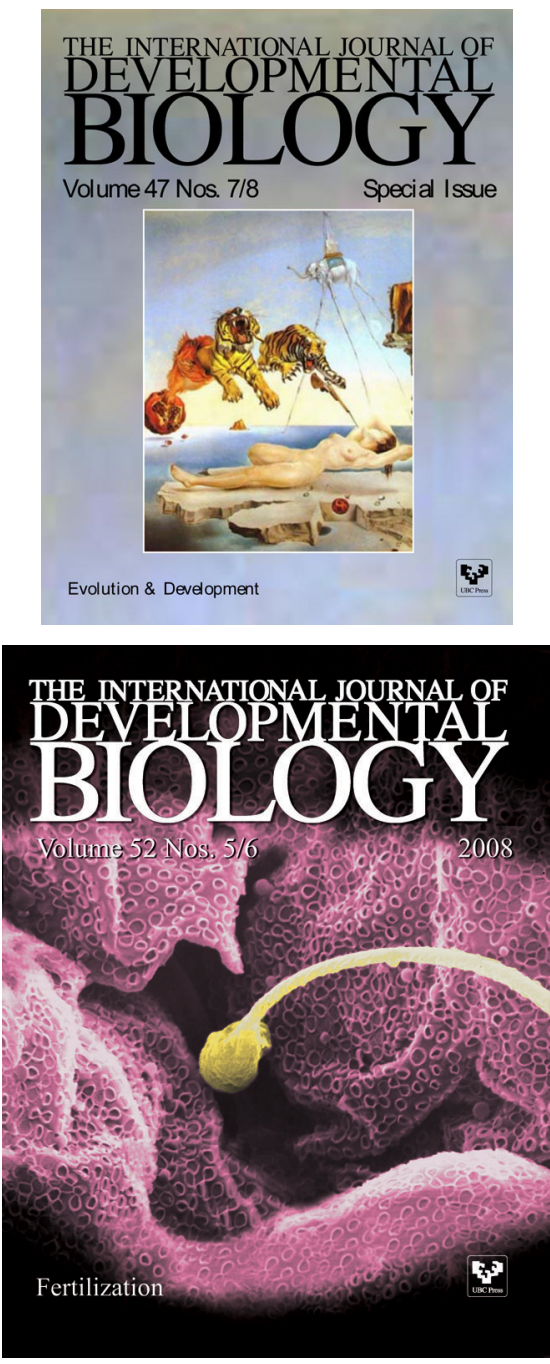